\title{
Osmium- and Ruthenium-Based Phosphorescent Materials: Design, Photophysics, and Utilization in OLED Fabrication
}

\author{
Pi-Tai Chou*[a] and Yun Chi*[b]
}

Keywords: Osmium / Ruthenium / N ligands / Phosphorescence / Luminescence

Osmium(II) complexes possessing $\beta$-diketonate, quinolinate, diimine, and C-linked pyridyl azolate chelates reveal interesting structural and photophysical properties. Spectroscopic and dynamic measurements, in combination with theoretical analyses, have provided an important understanding of the electronically excited state properties of these complexes, such as the energy gap and nature of the lower lying states, rate for intersystem crossing, and the efficiency of corresponding radiative decay and nonradiative deactivation processes. This review also reports on the synthetic processes that lead to the neutral $\mathrm{Os}^{\mathrm{II}}$ and $\mathrm{Ru}^{\mathrm{II}}$ complexes that possess two trans-substituted phosphane donor ligands together with two anti-parallel, aligned azolate chromophores. Considerable efforts have been made to focus on utilizing these emitting materials as phosphorescent dopants for practical PLED and OLED fabrication. Consequently, the interplay between these emitting materials and device configurations is discussed.

() Wiley-VCH Verlag GmbH \& Co. KGaA, 69451 Weinheim, Germany, 2006)

\section{Introduction}

Owing to their versatility and potential in optical sensing and sensitization, ${ }^{[1]}$ as well as in constructing a wide variety of photoresponsive molecular electronics, ${ }^{[2]}$ research on the photophysics and photochemistry of transition-metal complexes has been revitalized and has attracted much recent attention. Particularly, a wide range of metal elements with distinctive d-shell configurations have been employed in or-

[a] Department of Chemistry, National Taiwan University, Taipei 106, Taiwan

E-mail: chop@ntu.edu.tw

[b] Department of Chemistry, National Tsing Hua University, Hsinchu 300, Taiwan

E-mail: ychi@mx.nthu.edu.tw der to study their luminescent properties. The influence of metal atoms, together with the modification of ligand architectures, continuously provides an attractive theme for further investigations. There has been an intensive investigation into the emissive $\mathrm{Re}^{\mathrm{I}}$ complexes, in particular those with a functionalized diimine ligand attached to the $\mathrm{fac}$ $\left[\operatorname{Re}(\mathrm{CO})_{3}\right]$ unit. $^{[3]}$ The diimine group, exhibiting diversified electronic properties, has rendered a possibility for fine-tuning the excited state properties and luminescent efficiencies. In sharp contrast, relatively less attention has been focused on the behavior of their isoelectronic and isostructural $\mathrm{Os}^{\mathrm{II}}$ analogues. In an attempt to explore their chemistry and corresponding photophysical properties, we have directed our research efforts specifically to the preparation and charac-

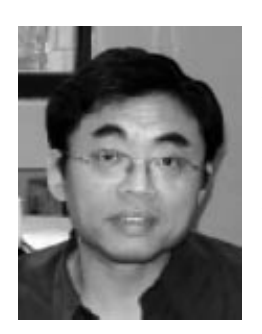

Pi-Tai Chou received his Ph.D. degree from Florida State University, Tallahassee, in 1985, and is currently a Chair Professor at National Taiwan University. He was an assistant professor at University of South Carolina (1988-1994) and a professor of National Chung Cheng University, where he was the departmental chairman from 1997 to 1999. His research interests span the area of ultrafast laser spectroscopy, syntheses, and photophysics of materials suited for OLED, solar energy cell, and nanotechnology.

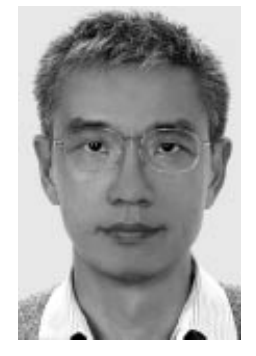

Yun Chi obtained his Ph.D. degree from UIUC, Illinois, in 1986, and was promoted to Professor of Natural Sciences at National Tsing Hua University in 2003. His past academic endeavors cover the chemistry of polymetallic carbonyl clusters, which is important for understanding the catalysts used by petroleum industries for production of new polymers and commodity organics. His current research focuses on subjects involving preparation of metal-containing thin films and nanomaterials by using chemical vapor deposition, as well as synthesis of transition-metal complexes for OLEDs and photovoltaics. 
terization of a great range of $\mathrm{Os}^{\mathrm{II}}$ complexes. With an ingenious design of ligated chromophores, we believe that the luminescent $\mathrm{Os}^{\mathrm{II}}$ complexes may serve as new models for probing a variety of fundamental characteristics in both ground and excited states (vide infra).

From the application point of view, organometallic complexes possessing heavy transition-metal elements are crucial for the fabrication of phosphorescent organic lightemitting diodes (OLEDs).$^{[4]}$ The strong spin-orbit coupling effectively promotes singlet-to-triplet intersystem crossing, as well as enhances the subsequent transition from the triplet excited state to the ground state, the results of which then facilitate strong electroluminescence by harnessing both singlet and triplet excitons. Theoretically, an internal phosphorescence quantum efficiency $\left(\eta_{\text {int }}\right)$ that can be as high as $100 \%$ could be achieved, ${ }^{[5]}$ such that these emitting materials would be superior to their fluorescence-only counterparts for which only singlet excitons can be utilized. This superiority leads to a continuous trend of shifting research endeavors to the heavy transition-metal-based emitters, among which intense research has been carried out on the system involving $\mathrm{Ir}^{\mathrm{III}}$ complexes ever since the seminal study on $\left[\operatorname{Ir}(\text { ppy })_{3}\right]$ (ppy $=2$-phenylpyridine) ${ }^{[6]}$ In comparison, although much less explored, Os(II) complexes may gain certain advantages, such as the reduction of radiative lifetime and hence a possibility of higher luminescent efficiency, over the traditional $\mathrm{Ir}^{\mathrm{III}}$ and $\mathrm{Pt}^{\mathrm{II}}$ emitting materials in OLED applications.

On one hand, this is probably due to the fact that Os in all emissive Os complexes possesses the unique +2 oxidation state. Hence, luminescent $\mathrm{Os}^{\mathrm{II}}$ complexes, in general, are expected to exhibit lower electrochemical oxidation potentials in $\mathrm{d} \pi$ orbitals relative to those of the iso-electronic $\mathrm{Ir}^{\mathrm{III}}$ complexes. Thus, unless $\mathrm{Os}^{\mathrm{II}}$ complexes are incorporated with strong $\pi$-accepting ancillary ligands such as $\mathrm{CO}$, the osmium $\mathrm{d} \pi$ orbitals will be destabilized, which results in an increase in the metal-to-ligand charge transfer (MLCT) contribution relative to typical $\pi-\pi^{*}$ transitions. Such a property, i.e. a short radiative decay time, may also improve the OLED device efficiencies by minimizing the unwanted triplet-triplet annihilation that occurs at a higher operating current density. ${ }^{[7]}$ On the other hand, in comparison to the luminescent $\mathrm{Pt}$ complexes possessing a similar $\mathrm{Pt}^{\mathrm{II}}+2$ oxidation state, the octahedral ligand arrangement of the $\mathrm{Os}^{\mathrm{II}}$ complexes would provide a prevailing environment for reducing the intermolecular interaction. This is mainly due to the fact that the planar arrangement and the $\mathrm{d}^{8}$ electronic configuration of the $\mathrm{Pt}^{\mathrm{II}}$ complexes are subject to aggregation, which leads to a possible $\pi-\pi$ stacking interaction in both fluid and solid solutions. ${ }^{[8]}$

Another subject of current interest is the development of luminescent, neutral $\mathrm{Ru}^{\mathrm{II}}$ complexes. ${ }^{[9]}$ Despite the fruitful progress on the transition-metal complexes above, a practical barrier to the commercialization of phosphorescent OLED technologies may result from the prohibitive cost of noble metals. With regard to the viability of application, there is an urgent need to develop phosphorescent emitting materials from less expensive precursors, among which $\mathrm{Ru}^{\mathrm{II}}$ serves as an alternative. Skepticism to this approach, however, might arise as a result of the weaker ligand field strength of $\mathrm{Ru}^{\mathrm{II}}$ as well as its smaller heavy-atom-effect, i.e. weak spin-orbit coupling, relative to the third-row transition metals. ${ }^{[10]}$ Nevertheless, recent progress has shown that $\mathrm{Ru}^{\mathrm{II}}$ complexes are suitable for decent OLED/PLED performance. Such success is apparently credited to the rational design of ligand structures through the standpoint of fundamental chemistry and photophysics. Accordingly, in this review, a certain focus will also be directed towards the synthesis, characterization, and utilization of the $\mathrm{Ru}^{\mathrm{II}}$ complexes, their excitation behavior, and the fabrication of efficient phosphorescent OLED devices.

\section{2. $\left[\mathrm{Os}(\mathrm{CO})_{3}\right]$ Derivatives}

\subsection{Diketonate Complexes}

Photophysical studies of lower oxidation state rhenium(I) complexes with the structural formula $f a c-\left[\operatorname{Re}(\mathrm{CO})_{3} \mathrm{X}(\mathrm{L})\right]$ ( $\mathrm{X}=$ halides and $\mathrm{L}=$ bidentate heterocycles such as $2,2^{\prime}$ bipyridine) have received considerable attention over the past two decades. ${ }^{[3,11]}$ The observed emission could originate from the ligand-centered $\pi-\pi^{*}$, intra- or interligand charge transfer, or even from the metal-to-ligand charge transfer (MLCT) states, depending on the nature of heterocyclic ligands. Moreover, the central metal cation would also impose notable influence on the photophysical properties of the complexes. This gives us the motivation to initiate the heretofore unexplored osmium(II) tricarbonyl analogues.

Accordingly, a series of $\beta$-diketonate complexes with the formula $\left[\mathrm{Os}(\mathrm{CO})_{3}(\mathrm{tfa})(\mathrm{LX})\right](\mathbf{1}-\mathbf{7})$ were synthesized from the Os dimer $\left[\mathrm{Os}_{2}(\mathrm{CO})_{6}(\mathrm{tfa})_{2}\right](\mathrm{tfa}=$ trifluoroacetate $)$ with the appropriate diketone reagent $(\mathrm{LX}) \mathrm{H}$ in a Carius tube. ${ }^{[12]}$

$$
\left[\mathrm{Os}_{2}(\mathrm{CO})_{6}(\mathrm{tfa})_{2}\right]+(\mathrm{LX}) \mathrm{H} \rightarrow\left[\mathrm{Os}(\mathrm{CO})_{3}(\mathrm{tfa})(\mathrm{LX})\right]+\mathrm{H}_{2}
$$

The remarkable variation in the photophysical properties of complexes 1-7 is summarized in Table 1 . For the hexafluoroacetylacetate complex $\mathbf{1}$, the lowest energy absorption at $336 \mathrm{~nm}$, with an extinction coefficient as low as $3000 \mathrm{M}^{-1} \mathrm{~cm}^{-1}$, is assigned to the ${ }^{1} \mathrm{MLCT}$ transition, while the corresponding emission appears at $\lambda_{\max }=545 \mathrm{~nm}$. The phosphorescent character is ascertained by its large Stokes shift and long radiative lifetime, $\tau_{\mathrm{r}}$, of ca. $7 \mu \mathrm{s}$, which is calculated by $\tau_{\mathrm{r}}=\tau_{\mathrm{p}} / \Phi\left(\tau_{\mathrm{p}}\right.$ : observed decay time, $\Phi$ : emission yield). Upon replacing one $\mathrm{CF}_{3}$ substituent with a tert-butyl or a phenyl group to form complexes $\mathbf{2}$ or $\mathbf{3}$, respectively, the emission is still dominated by phosphorescence, as indicated by its large Stokes shifted peak wavelength and drastic $\mathrm{O}_{2}$ quenching effect.

Replacement of the aromatic pendant with either $\alpha$ - or $\beta$-naphthalene to form $\mathbf{4}$ or $\mathbf{5}$, respectively, also gives rise to a unique phosphorescence with a peak wavelength at 560 and $540 \mathrm{~nm}$, respectively. However, in contrast to the sole phosphorescence for complexes 1-3 in both degassed and aerated $\mathrm{CH}_{2} \mathrm{Cl}_{2}$, dual emission that consists of fluorescence, i.e. $462 \mathrm{~nm}(4)$ and $455 \mathrm{~nm}(5)$, and phosphorescence was 
Table 1. Photophysical properties of complexes 1-7 in $\mathrm{CH}_{2} \mathrm{Cl}_{2}$ at room temperature.

\begin{tabular}{|c|c|c|c|c|c|c|}
\hline & Abs. $\lambda_{\max }[\mathrm{nm}]\left(\varepsilon \times 10^{3}\right)$ & $\mathrm{PL} \lambda_{\mathrm{em}}[\mathrm{nm}]$ & $\Phi[\%]^{[\mathrm{a}]}$ & $\tau_{\mathrm{f}} \approx 1 / k_{\mathrm{isc}}[\mathrm{ps}]$ & $\tau_{\mathrm{p}}[\mu \mathrm{s}]$ & Emitting states ${ }^{[\mathrm{b}]}$ \\
\hline 1 & $336(3)$ & 545 & 5.0 & {$[\mathrm{c}]$} & 0.35 & ${ }^{3} \mathrm{MLCT} /{ }^{3} \pi \pi^{*}(11.0 \%)$ \\
\hline 2 & $321(7)$ & 507 & 4.9 & $-[c]$ & 5.0 & ${ }^{3} \mathrm{MLCT} /{ }^{3} \pi \pi^{*}(7.0 \%)$ \\
\hline 3 & $347(14.7)$ & 520 & 16.2 & 0.48 & 14 & ${ }^{3} \mathrm{MLCT} /{ }^{3} \pi \pi^{*}(4.0 \%)$ \\
\hline 4 & 375 (13.6) & $462,{ }^{[\mathrm{d}]} 560$ & 7.9 & 3.64 & 11 & ${ }^{3} \pi \pi^{*}(1.3 \%)$ \\
\hline 5 & $355(17.2)$ & $455^{[\mathrm{d}]} 540$ & 13.5 & 6.71 & 19 & ${ }^{3} \pi \pi^{*}(1.0 \%)$ \\
\hline 6 & 316 (17.6), 438 (19.8) & 550,690 & 1.2 & 120 & 14 & ${ }^{1} \pi \pi^{*}{ }^{3} \pi \pi^{*}(\approx 0 \%)$ \\
\hline 7 & $378(20.7), 453(11.3)$ & $575,740^{[\mathrm{e}]}$ & 11.0 & 2100 & {$[\mathrm{f}]$} & ${ }^{1} \pi \pi^{*}(\approx 0 \%)$ \\
\hline
\end{tabular}

[a] The solution was degassed with at least three freeze-pump-thaw cycles. For $\mathbf{6}$, the reported $\Phi$ value is the sum of florescence and phosphorescence. [b] Values in parentheses are the percentage of ${ }^{3} \mathrm{MLCT} /{ }^{3} \pi \pi$. [c] $\tau_{\mathrm{f}}$ is shorter than the system response of $150 \mathrm{fs}$. [d] The emission band was only detectable in an aerated solution. [e] The phosphorescence was acquired by laser ( $355 \mathrm{~nm})$ excitation in a $77-\mathrm{K}$ methylcyclohexane glass. [f] The phosphorescence intensity was too weak to resolve the lifetime.<smiles>[R]c1cc(C(F)(F)F)c(C(=O)O)c(=O)o1</smiles>

$\mathrm{R}=$

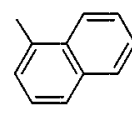

4

$\mathrm{R}=$

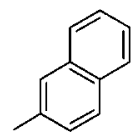

5

$1: R=C F_{3} ; 2: R=t B n ; 3: R=P h$

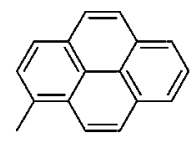

6

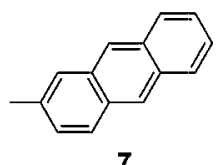

resolved for $\mathbf{4}$ and $\mathbf{5}$ under aerated conditions, which indicates their relatively slow $\mathrm{S}_{1}-\mathrm{T}_{1}$ intersystem crossing rate, $k_{\text {isc }}$. Further substitution of pyrene (6) reveals drastically different excitation behaviors. This is confirmed by the observation of dual fluorescence $(550 \mathrm{~nm})$ and phosphorescence $(690 \mathrm{~nm})$ with a ca. 1:1.2 intensity ratio. In contrast, complex 7 exhibits only fluorescence, regardless of whether it is in degassed or aerated $\mathrm{CH}_{2} \mathrm{Cl}_{2}$, as supported by the excessive short radiative lifetime of $2.1 \mathrm{~ns}$. Nevertheless, weak phosphorescence with a peak wavelength at ca. $740 \mathrm{~nm}$ was resolved for 7 in a $77 \mathrm{~K}$ methylcyclohexane glass matrix.

The changes of the lowest energy excited state character can be rationalized by the $\pi$-electron conjugation introduced by the polyaromatic pendant at the diketonate chromophore, which increases (decreases) the $\pi\left(\pi^{*}\right)$ energy of both $\mathrm{S}_{1}$ and $\mathrm{T}_{1}$ states in a qualitative manner. The fast $k_{\text {isc }}$ observed in 1-3 can be rationalized by mixed MLCT and $\pi-\pi^{*}$ character in both $\mathrm{S}_{1}$ and $\mathrm{T}_{1}$ manifolds. If intersystem crossing takes place mainly from the $S_{1} \rightarrow T_{1}$ pathway, the corresponding rate constant, $k_{\text {isc }}$, is proportional to $\frac{<T_{1}\left|H_{\mathrm{SO}}\right| S_{1}>^{2}}{\left(\Delta E_{S_{1}-T_{1}}\right)^{2}}$, where $H_{\text {so }}$ is the Hamiltonian for the spinorbit coupling and $\Delta E_{S_{1}-T_{1}}$ is the energy difference between singlet $\left(\mathrm{S}_{1}\right)$ and triplet $\left(\mathrm{T}_{1}\right)$ states. The mixing of $\pi-\pi^{*}$ and MLCT in both $S_{1}$ and $T_{1}$ states leads to the $S_{1} \rightarrow T_{1}$ intersystem crossing that incorporates the $<^{1} \mathrm{~d}_{\pi} \pi^{*}\left|H_{s o}\right|^{3} \pi \pi^{*}>$ or $<^{3} \mathrm{~d}_{\pi} \pi^{*}\left|H_{s o}\right|^{1} \pi \pi^{*}>$ term. The net result induces the change in orbital angular momentums, i.e. $\mathrm{d} \pi \rightarrow \pi$ coupled with the flip of the electron spin, so that the transition has a significantly large first-order spin-orbit coupling term, which results in a drastic enhancement of the intersystem crossing. [13]

Accordingly, among complexes 1-7, as shown in Table 1, the greatest $\mathrm{MLCT} / \pi-\pi^{*}$ mixing in $\mathbf{1}$ and $\mathbf{2}$ gives rise to ultrafast, system-response-limited $\left(>10^{13} \mathrm{~s}^{-1}\right) k_{\text {isc }}$. Because of the lack of MLCT/ $\pi-\pi^{*}$ state mixing in $\mathbf{6}, k_{\text {isc }}$ decreases drastically to $9.2 \times 10^{9} \mathrm{~s}^{-1}$. Apparently, because of the lack of MLCT, complexes 6 and 7 mainly undergo a ${ }^{1} \pi \pi^{*} \rightarrow$ ${ }^{3} \pi \pi^{*}$ intersystem crossing, in which the coupling between orbital and spin angular momentum, and hence the $<^{1} \pi \pi^{*}\left|H_{s o}\right|^{3} \pi \pi^{*}>$ term, should be rather small owing to negligible changes in orbital angular momentum that can couple with the flip of electron spin. In other words, there is a small first-order spin-orbit coupling to enhance the intersystem crossing.

To investigate the effect of the anionic ligands $\mathrm{X}$ in this class of osmium(II) complexes, we prepared the dibenzoylmethanate complexes using the reaction sequence and the corresponding anion exchange protocols that is depicted.

$\left[\mathrm{Os}_{2}(\mathrm{CO})_{6}(\mu-\mathrm{X})_{2}\right]+(\mathrm{dbm}) \mathrm{H} \rightarrow\left[\mathrm{Os}(\mathrm{CO})_{3} \mathrm{X}(\mathrm{dbm})\right], \mathrm{X}=$ tfa (8) and I (11)

$(8)+\mathrm{NaCl}, \mathrm{NaBr}$ or $\mathrm{NH}_{4} \mathrm{SCN} \rightarrow\left[\mathrm{Os}(\mathrm{CO})_{3} \mathrm{X}(\mathrm{dbm})\right], \mathrm{X}$ $=\mathrm{Cl}(\mathbf{9}), \mathrm{Br}(\mathbf{1 0})$, and $\mathrm{SCN}$ (12)

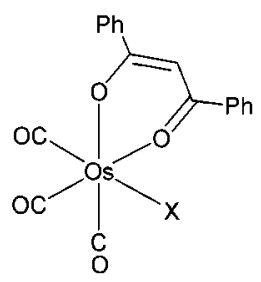

$8: \mathrm{x}=\mathrm{CF}_{3} \mathrm{CO}_{2} ; 9: \mathrm{x}=\mathrm{Cl}$; 10: $x=B r ; 11: x=1 ; 12: x=S C N$

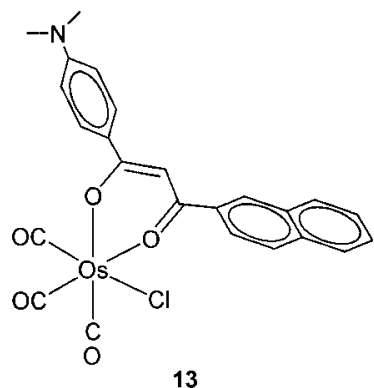

Table 2 shows their photophysical data, for which the lowest-energy absorption band in the region of ca. $367-$ $380 \mathrm{~nm}$ can be assigned as an intraligand $\pi-\pi^{*}$ transition of the chelating dbm ligand, together with a small proportion of MLCT character. ${ }^{[14]}$ The emission lifetime is unusually long ( $\geq 29 \mu \mathrm{s}$ ), giving characteristics of the longlived phosphorescent emission and quantum yields approaching the level $0.08-0.13$. The only exception is the iodide complex $11(\Phi=0.007)$ - which could originate from photoinduced dissociation involving the weak Os-I bond which exhibits a decrease in phosphorescence upon prolonged photolysis. The hypsochromic shift of the emission peak maximum follows the order $\mathrm{tfa} \approx \mathrm{SCN}>\mathrm{Cl}>\mathrm{Br}>$ 
Table 2. Photophysical properties and electrochemical data of complexes 8-12 in $\mathrm{CH}_{2} \mathrm{Cl}_{2}$ at room temperature.

\begin{tabular}{lllllll}
\hline & Formula & Abs. $\lambda_{\max }[\mathrm{nm}]\left(\varepsilon \times 10^{3}\right)$ & $\lambda_{\mathrm{em}}[\mathrm{nm}]^{[\mathrm{a}],[\mathrm{b}]}$ & $\tau_{\mathrm{o}}[\mu \mathrm{s}]^{[\mathrm{a}],[\mathrm{b}]}$ & $\Phi_{\mathrm{em}}$ & $k_{\mathrm{r}}\left[10^{3} \mathrm{~s}^{-1}\right]^{[\mathrm{c}]}$ \\
\hline $\mathbf{8}$ & {$\left[\mathrm{Os}(\mathrm{CO})_{3}(\mathrm{tfa})(\mathrm{dbm})\right]$} & $280(22), 367(20)$ & $538(541)$ & $64(3.0)$ & 0.13 & 2.02 \\
$\mathbf{9}$ & {$\left[\mathrm{Os}(\mathrm{CO})_{3} \mathrm{Cl}(\mathrm{dbm})\right]$} & $285(19), 372(16)$ & $557(537)$ & $46(9.1)$ & 0.13 & 2.76 \\
$\mathbf{1 0}$ & {$\left[\mathrm{Os}(\mathrm{CO})_{3} \mathrm{Br}(\mathrm{dbm})\right]$} & $278(19), 375(16)$ & $563(561)$ & $29(4.2)$ & 0.08 & 2.82 \\
$\mathbf{1 1}$ & {$\left[\mathrm{Os}(\mathrm{CO})_{3} \mathrm{I}(\mathrm{dbm})\right]$} & $278(24), 380(14)$ & $574(602)$ & $0.72,38(2.7)$ & 0.007 & 0.18 \\
$\mathbf{1 2}$ & {$\left[\mathrm{Os}(\mathrm{CO})_{3}(\mathrm{SCN})(\mathrm{dbm})\right]$} & $277(26), 372(15)$ & $539(545)$ & $53(3.4)$ & 0.13 & 2.49 \\
\hline
\end{tabular}

[a] Excitation wavelength: $380 \mathrm{~nm}$. [b] Data in parenthesis were obtained in the thin solid films. Note that a faster decay component $(<0.2 \mu \mathrm{s})$ was observed for $\mathbf{8}-\mathbf{1 2}$ in the solid state possibly due to the defective sites. Its integrated intensity is $<10 \%$ and is thus neglected. [c] $k_{\mathrm{r}}=\Phi_{\mathrm{em}} / \tau$.

I, which is proportional to the electron-donor strength of the anion that destabilizes the metal-centered HOMO, hence decreasing the energy gap.

We also made an attempt to probe the fundamentals of the triplet-state properties based on this inherent molecular design involving the related $f a c-\left[\mathrm{Os}(\mathrm{CO})_{3}\right]$ unit. ${ }^{[15]}$ One intriguing topic relevant to triplet-state properties should be ascribed to the triplet-state intramolecular charge transfer (TSICT) process. ${ }^{[16]}$ It has been reported that the micelle or polymer encapsulated organic chromophore, together with the external heavy atom effect, may resolve room-temperature phosphorescence. ${ }^{[17]}$ However, the resulting heterogeneous and rigid environments make the investigation of the solvation-associated properties impractical. As a result, photophysical properties associated with TSICT, such as the solvation relaxation dynamics and the steady-state consequence, e.g. the phosphorescence solvatochromism, are not attainable in solvents with a low viscosity. Our strategic design, in contrast, is much more simple (c.f. complex 13) and involves the utilization of the $\left[\mathrm{Os}(\mathrm{CO})_{3} \mathrm{Cl}\right]$ fragment to support an asymmetrical $\beta$-diketonate ligand, composed of an $N, N$-dimethylaniline and a 2-naphthylene substituent that serve as the electron donor and the acceptor, respectively. ${ }^{[18]}$ As the attached heavy-metal fragment $\left[\mathrm{Os}(\mathrm{CO})_{3} \mathrm{Cl}\right]$ generally possesses a large energy gap for the metal dd and MLCT transitions, ${ }^{[19]}$ the organic chromophore of interest, i.e. $\beta$-diketonate, is expected to lie in the lower-lying excited states.

Figure 1 shows the absorption and emission spectra of 13 in various solvents. The different relaxation dynamics of fluorescence and phosphorescence allowed us to resolve each component. ${ }^{[15]}$ In aerated cyclohexane, this molecule exhibits distinct dual fluorescence at $470 \mathrm{~nm}$ and phosphorescence at $570 \mathrm{~nm}$ with a sum of near unitary quantum efficiency. As the solvent polarity increases, drastic polarity dependence in emission spectra is observed. Evidently, both the fluorescence and phosphorescence undergo notable bathochromatic shift and give rise to an exceedingly broad emission signal. Changes in dipole moment for the $S_{1}$ and $\mathrm{T}_{1}$ states with respect to the ground state are deduced to be 18.0 and 11.9 Debye, respectively, with the Lippert-Mataga equation. ${ }^{[20]}$ The appreciable difference in dipolar changes implies the intrinsic difference in the electron-density distribution between $S_{1}$ and $T_{1}$ states. Further theoretical analysis indicates that the $T_{1}$ state possesses a substantial contribution $(\approx 10 \%)$ from the MLCT transition originating from the osmium $\mathrm{d} \pi$ orbital to the $\pi$ system of the 2-naphthyl moiety, whereas the $S_{1}$ state is dominated by a $\pi \pi^{*}$ configuration. Thus, the redistribution of $\pi$ electron density because of the charge transfer should be less emphasized in the $T_{1}$ state, rationalizing its smaller dipolar change. Such intrinsic, subtle differences in charge-transfer properties are intriguing and worthy to pursue further from a theoretical standpoint.

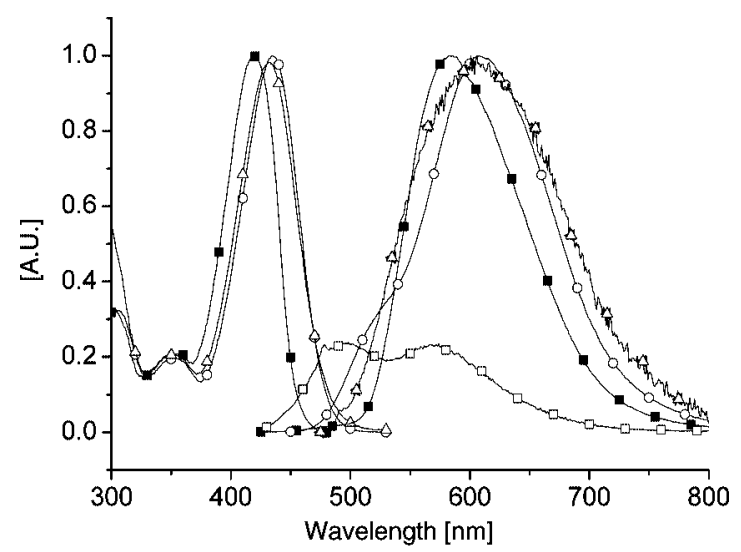

Figure 1. The absorption and steady-state emission spectra of $\mathbf{1 3}$ at $298 \mathrm{~K}$ in degassed cyclohexane (-口-), dichloromethane (-O-), and acetonitrile (- $\Delta-$-). The trace (- $\square-)$ denotes the emission spectrum of 13 in aerated cyclohexane.

\subsection{Quinolinolate Complexes}

Providing that the osmium fragment $\left[\mathrm{Os}(\mathrm{CO})_{3} \mathrm{X}\right]$ of $\beta$ diketonate complexes serves as a prototype to facilitate the intersystem crossing, other chelating anions such as quinolinolate have also been explored in an attempt to reveal their phosphorescent characters. ${ }^{[21]}$ This issue is motivated by the consideration that aluminum quinolinolate and its homologues were extensively tested for applications as the emitting or the electron-transporting materials in OLEDs. ${ }^{[22]}$

Four osmium(II) quinolinolate complexes 14-17 were synthesized, which provide a good example of the structural modifications that influence the basic photophysical properties. Table 3 summarizes the peak wavelengths of the lowest-energy absorption and other important photophysical data. The room-temperature absorption and emission spectra of complexes 14-17 in toluene are shown in Figure 2. The lower-lying absorption peak located at near 420 $450 \mathrm{~nm}$ is derived from a $\pi-\pi^{*}$ transition with a significant contribution from the intraligand charge transfer (ILCT) 
transition. ${ }^{[23]}$ This delineation is in good agreement with the ca. 20-nm bathochromic shift of a similar absorption band of $\mathbf{1 7}$, for which fluorine substitution at the 5-position is expected to markedly lower the $\pi-\pi$ energy gap of the quinolinolate fragment because of the resonance (i.e. mesomeric) effect. ${ }^{[24]}$ The assignment to the MLCT band is discarded owing to the lack of electronic dependence on the metal environment in the iodide complex 15.<smiles></smiles>

14: $\mathrm{X}=\mathrm{CF}_{3} \mathrm{CO}_{2}$ 15: $X=1$<smiles></smiles>

16: $\mathrm{X}=\mathrm{CF}_{3} \mathrm{CO}_{2}$

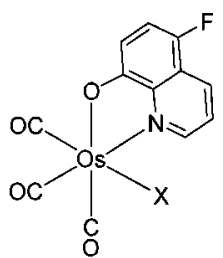

17: $\mathrm{X}=\mathrm{CF}_{3} \mathrm{CO}_{2}$
As depicted in Figure 2, except for the fluorine-substituted complex 17 in which only fluorescence could be resolved, complexes 14-16 revealed two distinct bands, the intensity ratios of which varied according to the quinolinolate ligands and the anionic ancillary ligands. The shorterwavelength band, showing characteristics of a short lifetime $(<2 \mathrm{~ns}$, see Table 3$)$, is classified as fluorescent emission, while the longer-wavelength band can be assigned to the respective phosphorescence on the basis of its relatively much longer lifetime $(>1 \mu \mathrm{m})$ and drastic quenching effect under oxygen. It is believed that both of these emissions are dominated by typical $\pi-\pi^{*}$ transition in combination with ILCT [phenolate site $(\pi) \rightarrow$ pyridine site $\left(\pi^{*}\right)$ ] character. The latter transition, in part, incorporates the transfer of electron densities from the oxygen atom of the phenolate fragment to the $\pi^{*}$ orbitals of the fused ring system. The fluorine atom in complex $\mathbf{1 7}$ exhibits the mesomeric effect, ${ }^{[24]}$ which results in the decrease in electronic transition energy, with a consequent bathochromic shift in both the absorption and emission bands.

The variation in the intensity of dual emissions, i.e. fluorescence vs. phosphorescence, can be correlated with the relaxation dynamics of the $S_{1} \rightarrow T_{1}$ intersystem crossing. In comparison with complex 14, the addition of a 2-methyl group in 16 enhances $k_{\text {isc }}$ threefold, which may be rationalized by the increase in density of the final vibronic states $\left(T_{1}\right)$ having the same energy as the initial states $\left(S_{1}\right)$. For complex 17, the mesomeric effect introduced by the fluorine atom at the 5-position of the quinolinolate would result in the retardation of intersystem crossing in a qualitative manner and hence give the reduction of $k_{\text {isc }}$. However, in the case of iodide-substituted complex 15, the phosphorescence is significantly increased, plausibly because of the additional iodide heavy-atom effect that drastically increases the rate of intersystem crossing (vide infra). ${ }^{[25]}$

Table 3. Photophysical properties of complexes 14-17 in degassed toluene at room temperature.

\begin{tabular}{llllll}
\hline & Abs. $\lambda_{\max }[\mathrm{nm}]\left(\varepsilon \times 10^{3}\right)$ & $\mathrm{PL} \lambda_{\max }[\mathrm{nm}]$ & $\Phi[\%]^{[\mathrm{a}]}$ & Fluorescence $[\mathrm{ns}]$ & ${\text { Phosphorescence }[\mu s]^{[\mathrm{b}]}}$ \\
\hline $\mathbf{1 4}$ & $424(3.3)$ & 526,635 & 1.4 & 0.55 & 33.1 \\
$\mathbf{1 5}$ & $430(4.1)$ & 520,650 & 2.4 & 0.15 & 3.8 \\
$\mathbf{1 6}$ & $421(3.4)$ & 520,650 & 0.2 & 0.21 & 21.6 \\
$\mathbf{1 7}$ & $443(2.9)$ & 560,689 & 1.1 & 1.10 & - \\
\hline
\end{tabular}

[a] The solution was degassed with at least three freeze-pump-thaw cycles. The reported $\Phi$ value is the sum of fluorescence and phosphorescence. [b] The phosphorescence lifetime was measured by a direct laser flash experiment.

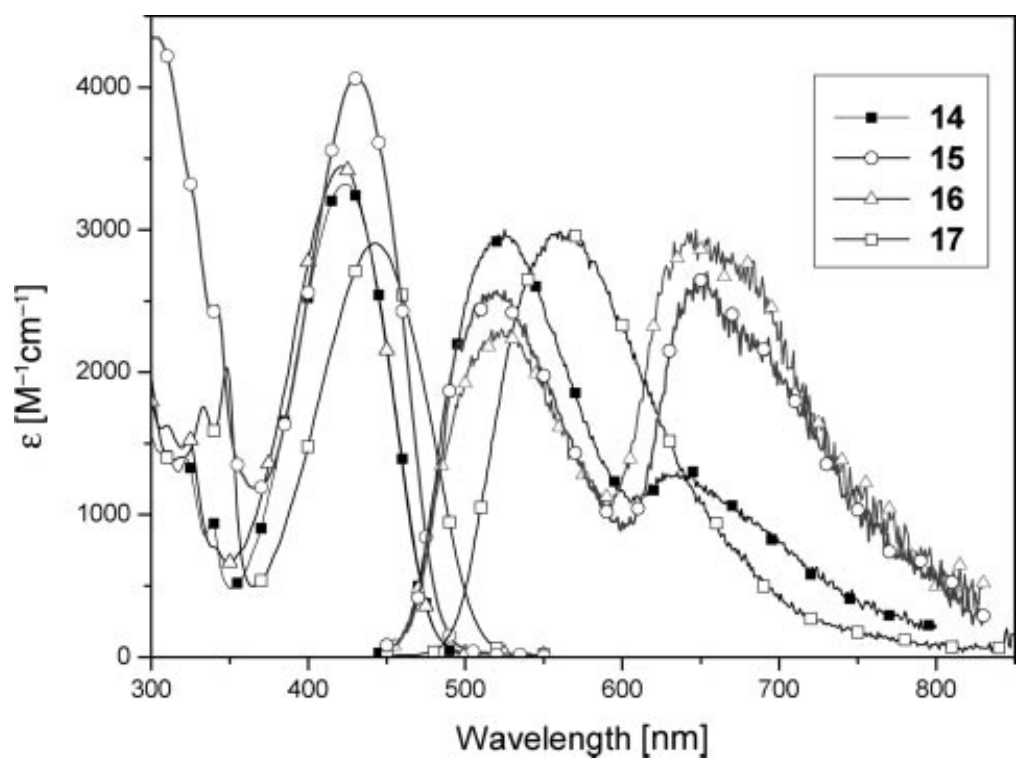

Figure 2. UV/Vis absorption and normalized emission spectra of $\mathbf{1 4}(-\mathbf{-}-), \mathbf{1 5}\left(-\mathrm{O}_{-}\right), \mathbf{1 6}(-\Delta-)$, and $\mathbf{1 7}$ (- $\left.\square-\right)$ in toluene at room temperature. 


\section{3. $\left[\mathrm{Os}(\mathrm{CO})_{2}\right]$ Derivatives}

\subsection{Diimine Complexes}

Dicarbonyl osmium(II) complexes of the type [Os(diimine $(\mathrm{CO})_{2} \mathrm{I}_{2}$ ] contain both $\pi$-donating iodide ligands and an accepting diimine ligand with low energy $\pi^{*}$ orbitals. These osmium(II) complexes exhibit pseudo-octahedral geometry, and the iodide and carbonyl ligands are located at the trans and cis positions, respectively. ${ }^{[26]}$ The main interest in initiating this investigation was to shed light on the nature of the lowest excited state; for example, whether these complexes display the basic characteristics of the usual metal-to-ligand charge transfer excited state (MLCT) or a state with a substantial amount of the halide-to-ligand charge transfer (XLCT) character.

It is noted that these $\mathrm{Os}^{\mathrm{II}}$ complexes exhibit much stronger room-temperature iodide-to-ligand phosphorescence than that of their ruthenium analogues. Such a difference is attributed to an increase in the all osmium ligand bonding strength relative to that of the second row ruthenium counterparts, which affords an increase in the energy of the metal-centered dd state. Therefore, this dd state is more difficult to populate in the osmium derivatives, which shows a notable increase in luminous intensity. Conversely, if the metal-centered dd state is more easily populated, which is more likely to occur in the ruthenium complexes, the complex may relax back to the ground state through nonradiative means and exhibit a great loss in the emission efficiency. ${ }^{[27]}$ DFT calculations on complex $\mathbf{1 8 b}$ confirm that the room-temperature emission originates from mixed XLCT $(\approx 70 \%)$ and MLCT $(\approx 30 \%)$ as a result of the lower oxidation potential of the iodide ligand. Replacing the diimine ligand from bipyridine (or phenanthroline) with the pyridyl benzoxazole ligand leads to a significant bathochromatic shift of the emission signal. The result implies that the benzoxazole ligand of $\mathbf{1 9}$ possesses a lower energy $\pi^{*}$ orbital relative to that of the bipyridine (or phenanthroline) ligands, which in turn gives a reduction in the energy gap for the MLCT/XLCT excited states.

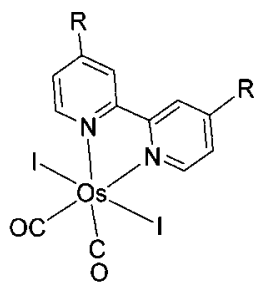

18: $R=H ; 18 a: R=t B u$<smiles></smiles>

18b

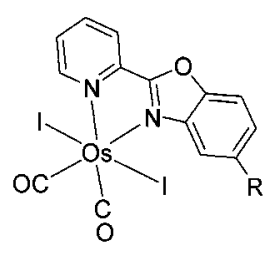

19: $R=H ; 19 a: R=t B u$

\subsection{Pyridyl Azolate Complexes}

The C-linked 2-pyridyl azolate belongs to a class of chelating ligands for which the large difference in the electronic properties of the pyridyl and the azolate fragment would render a larger ligand-centered $\pi-\pi^{*}$ energy gap. Such a property is very desirable for the generation of rarely observed blue phosphorescence. Furthermore, the disparity in electron distribution between the azolate and pyridyl fragments may provide a synergic effect such that the electron density transfers from the azolate to the cationic metal center and back to the pyridyl fragment, giving a delocalized and stabilized metal-chelate bonding interaction.

Treatment of 3-trifluoromethyl-5-(2-pyridyl)pyrazole (fppz)H and $\mathrm{Os}_{3}(\mathrm{CO})_{12}$ afforded only one complex, 20, in moderate yield. ${ }^{[28]}$ For reactions with the related triazole chelate, two isomeric complexes, 21 and 22, were observed for the direct treatment of 3-tert-butyl-5-(2-pyridyl)triazole (bptz)H with $\mathrm{Os}_{3}(\mathrm{CO})_{12}{ }^{[29]}$ Separation of products was achieved by using their marked solubility differences in acetone, where the less soluble isomer $\mathbf{2 1}$, which is structurally related to complex $\mathbf{2 0}$, can readily be obtained as a crystalline solid, while isolation of the second complex 22 required repeated extraction and slow diffusion of hexane vapor into a saturated acetone solution at room temperature.

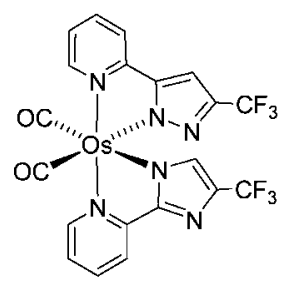

20

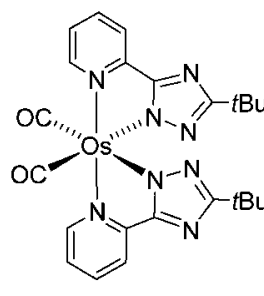

21

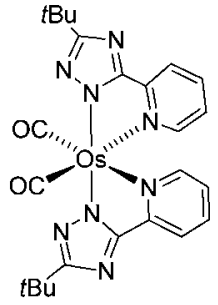

22
It is notable that the pyridyl fragments in complexes 20 and $\mathbf{2 1}$ are both located at the mutual trans position, while the pyridyl groups in complex 22 are located trans to the cis-oriented carbonyl ligands.

The corresponding photophysical data are summarized in Table 4. For complex 20, the lowest-energy absorption bands at ca. $310 \mathrm{~nm}$ are ascribed to the ligand-centered $\pi-$ $\pi^{*}$ transitions, while the corresponding MLCT transitions could be hidden under the more intense $\pi-\pi^{*}$ transitions. The emission spectrum exhibits a distinct vibronic feature with $\lambda_{\max }$ at 430,457 , and ca. $480 \mathrm{~nm}$ in $\mathrm{CH}_{3} \mathrm{CN}$. The fact that the entire emission band originates from a common excited-state species is ascertained by the same fluorescence excitation spectra throughout the monitored wavelengths of $420-600 \mathrm{~nm}$. This observation leads us to propose that the emissive state mainly possesses a ligand-centered ${ }^{3} \pi \pi^{*}$ character.

Table 4. Photophysical properties of complexes 20-22 in degassed $\mathrm{CH}_{3} \mathrm{CN}$ at room temperature.

\begin{tabular}{lllll}
\hline & Abs. $\lambda_{\max }[\mathrm{nm}]$ & PL $\lambda_{\max }[\mathrm{nm}]$ & Q.Y. $\Phi$ & $\tau[\mu \mathrm{s}]$ \\
\hline $\mathbf{2 0}$ & 311 & $430,457,480$ & 0.14 & 18.5 \\
$\mathbf{2 1}$ & 333 & $455,480,507$ & 0.42 & 39.9 \\
$\mathbf{2 2}$ & 340 & $460,483,515$ & 0.00046 & 0.026 \\
\hline
\end{tabular}

Figure 3 shows the UV/Visible absorption and emission spectra of both 21 and 22 in acetonitrile. Similarly, a structureless band with a maximum at $310-334 \mathrm{~nm}$ can be assigned to a triazolate-to-pyridine intraligand $\pi-\pi^{*}$ transition. For their emission spectra, complex 21 exhibits strong 
emission, with a quantum yield of 0.42 , for which distinct vibronic peak maxima appear at ca. 455, 480, and $507 \mathrm{~nm}$ in degassed $\mathrm{CH}_{3} \mathrm{CN}$ at $298 \mathrm{~K}$. Remarkable differences in emission properties were observed for 22. Although its emission profile looks quite similar to that of $\mathbf{2 1}$, this complex is nearly nonemissive with a quantum efficiency as low as $4.6 \times 10^{-4}$ in degassed $\mathrm{CH}_{3} \mathrm{CN}$ solution at $298 \mathrm{~K}$. This weak phosphorescence also correlates well with the observed fast relaxation dynamics, in which the lifetime of phosphorescence for $\mathbf{2 2}$ is measured to be as short as $26 \mathrm{~ns}$. It is also worth noting that a small but non-negligible fluorescence shoulder $\left(\lambda_{\max } \approx 420 \mathrm{~nm}, \tau_{\mathrm{f}}<200 \mathrm{ps}\right)$ could be resolved in 22 (Figure 3), although the rate of intersystem crossing is very fast, as indicated by the system-responselimited rising component of the phosphorescence $(<200 \mathrm{ps})$.

One possibility to account for the distinctive difference in emission behavior of $\mathbf{2 2}$ is that there exist certain excited states, possibly a metal-centered $\mathrm{d}-\mathrm{d}$ transition (i.e. ligand field, LF, transition), which results in weakening of the metal-ligand interaction as a result of their anti-bonding character and may thus act as an activator for the overall radiationless transition. ${ }^{[30]}$ However, this possibility was ruled out as none of the four lowest excited states, including two singlet and two triplet manifolds that were examined, possess the anticipated dd character. The inaccessibility of the dd excited state is believed to result from the strong ligand field strength of the triazolate chelates as well as of the CO ligands.

On the other hand, according to our TD-DFT calculation, a $T_{1}$ configuration in $\mathbf{2 2}$ could be reasonably attributed to a ${ }^{3} \pi \pi^{*}$ manifold, mixed to a great extent with small amounts of the ${ }^{3}$ MLCT character. ${ }^{[31]}$ By populating the $T_{1}$ excited state, a shift in the electron density from the metal center, $\mathrm{CO}$ ligands, and the triazolate moiety to the pyridine moiety occurs, which results in a further reduction of the already weakened Os-pyridine interactions in $\mathbf{2 2}$, for which the weakened bond lengths have been confirmed by singlecrystal X-ray analysis. As a result, in 22, the potential energy surface (PES) of $T_{1}$ might be so shallow that, under extreme conditions, a surface crossing of PESs between $T_{1}$ and $S_{0}$ is possible. As shown in Figure 4, upon excitation, fast $\mathrm{S}_{1}-\mathrm{T}_{n}$ intersystem crossing (ISC) must take place. It is plausible that ISC proceeds from $S_{1}$ to $T_{2}$ because of their closeness in energy, followed by a fast rate for $T_{2}$ to $T_{1}$ internal conversion $\left(\leq 1 \mathrm{ps}^{-1}\right)$. After population equilibrium, 22 can be thermally activated to certain vibrational levels close to the section of surface crossing to execute the radiationless deactivation through facile metal-ligand bond stretching. Thus, a dominant $\mathrm{T}_{1} \rightarrow \mathrm{S}_{0}$ radiationless transition caused by a "loose-bolt" effect might take place upon thermal activation. ${ }^{[32]}$

This discovery may allow a parallel comparison with the behavior of tris(cyclometalated) iridium complexes for which isolation of two geometrical isomers has been documented in the literature. ${ }^{[33]}$ Structural and spectroscopic data suggest that the facial isomers have stronger and more evenly distributed metal-ligand bond interactions, and are highly emissive in both fluid and solid states at room temperature. In contrast, the meridional isomers have much greater bond length alternations caused by the differing trans influences of anionic phenyl and neutral nitrogen donors such as pyridine or pyrazolate, and are significantly less emissive under identical conditions at room temperature. We speculate that this greater bond strength alternation then induces a similar effect upon electronic excitation, which is more likely to be responsible for the rapid radiationless deactivation observed in this $\mathrm{Ir}^{\mathrm{III}}$ system.

Moreover, treatment of complex $\mathbf{2 0}$ with a nitrogen donor ligand led to the formation of a new series of $\mathrm{Os}^{\mathrm{II}} \mathrm{com}$ plexes with formula $\left[\mathrm{Os}(\mathrm{fppz})_{2}(\mathrm{CO})(\mathrm{L})\right](\mathbf{2 3}, \mathrm{L}=4$-dimethylaminopyridine; $\mathbf{2 4}, \mathrm{L}=$ pyridine; $\mathbf{2 5}, \mathrm{L}=4,4^{\prime}$-bipyridine;

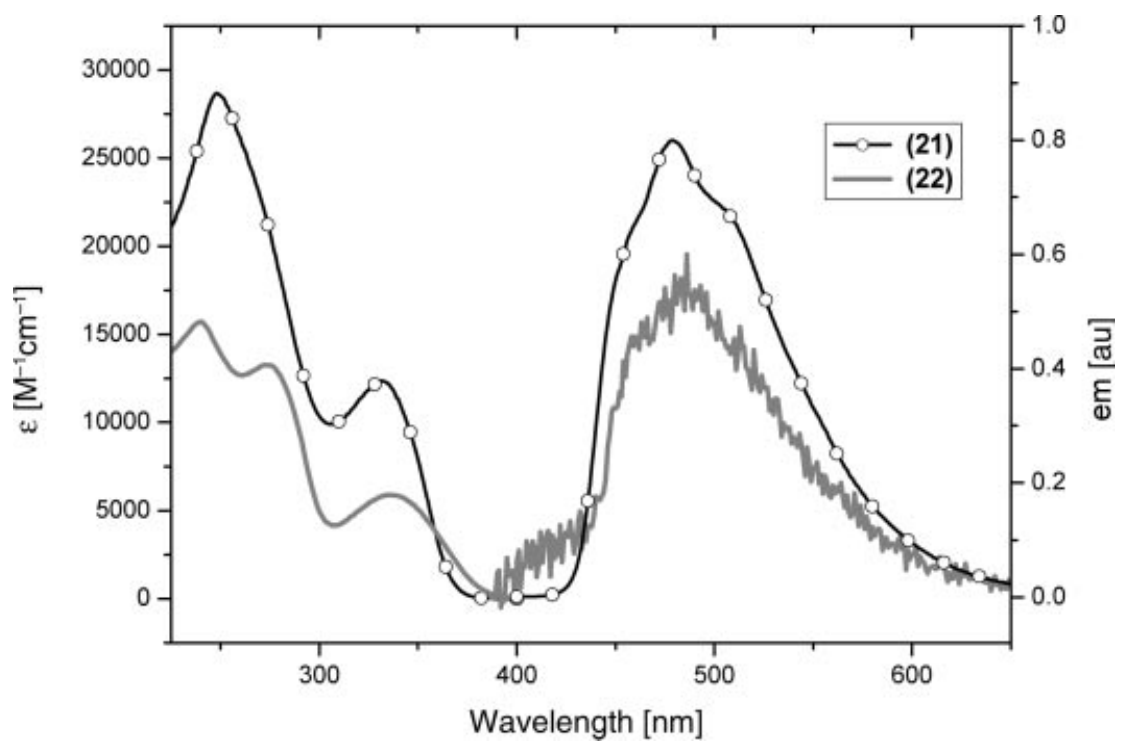

Figure 3. UV/Vis absorption and emission spectra of 21 (-o-) and $22(-)$ in $\mathrm{CH}_{3} \mathrm{CN}$ solution at room temperature. 


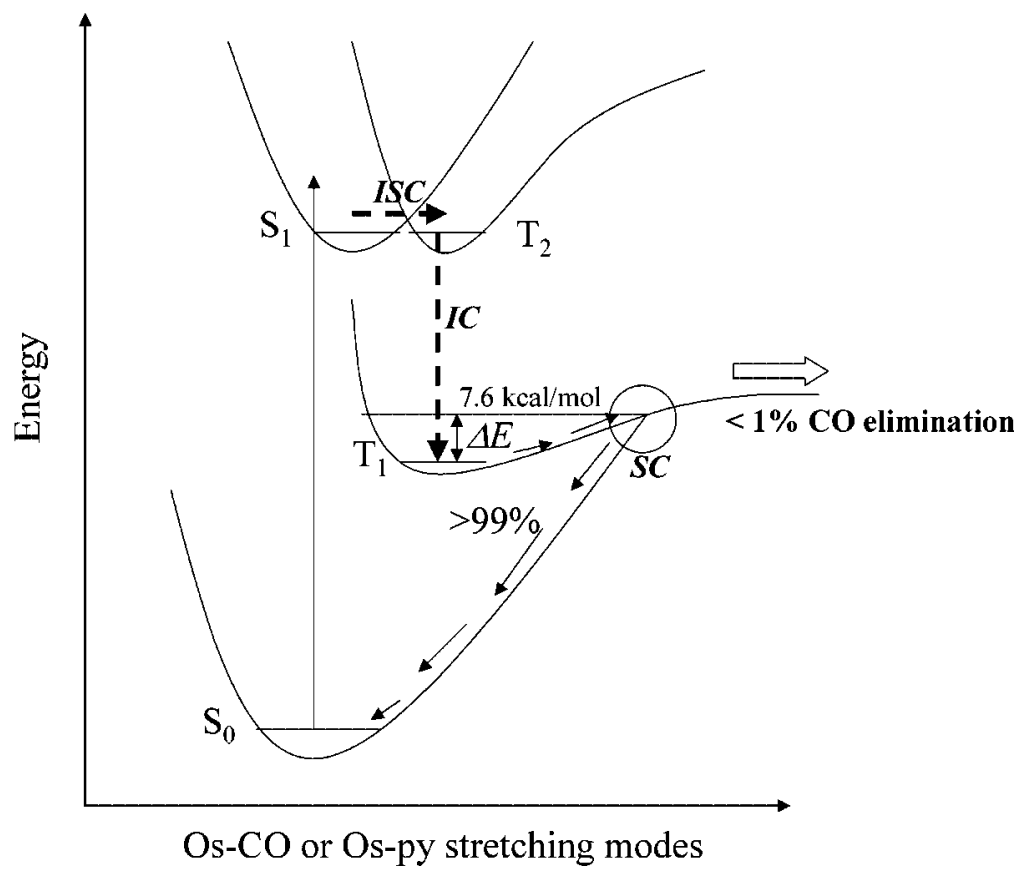

Figure 4. Energy levels of the lower-lying excited states and the proposed relaxation pathway for complex 22. ISC: intersystem crossing, IC: internal conversion. SC: surface crossing.

26, $\mathrm{L}=$ pyridazine; $27, \mathrm{~L}=$ 4-cyanopyridine); the remaining carbonyl ligands and the $\mathrm{N}$-heterocyclic ligand are located at the axial positions. ${ }^{[34]}$ Variation in the axial N-heterocyclic ligand leads to remarkable changes in photophysical properties such that the energy gap and the phosphorescence peak wavelength can be fine-tuned.<smiles></smiles>

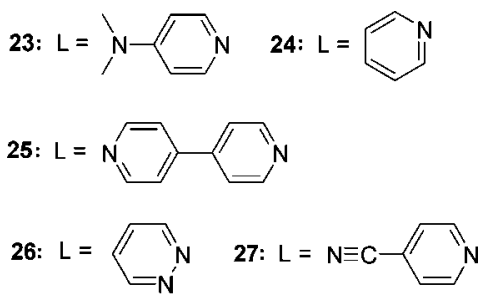

For complexes $\mathbf{2 3}$ and $\mathbf{2 4}$, the axial nitrogen donor ligand possesses an electron-rich aromatic $\pi$ system, which discourages its participation in the lowest-energy electronic transition. As a result, the phosphorescence originates from a combination of intraligand ${ }^{3} \pi \pi^{*}$ ( ${ }^{3}$ ILCT) and metal-toligand charge transfer transitions $\left({ }^{3} \mathrm{MLCT}\right)$ to the pyridyl fragments of the fppz chelates, and its peak wavelength is independent of the polarity of the solvent. This is confirmed by the observation of an only 18-nm red-shifted emission wavelength for complex $\mathbf{2 4}$ upon changing solvents from cyclohexane $(487 \mathrm{~nm})$ to acetonitrile $(\approx 505 \mathrm{~nm})$. In sharp contrast, complexes 25-27 exhibit mainly ligandto-ligand charge transfer (LLCT) transitions, with a transfer of electron density from the equatorial pyrazolate fragment to the axial nitrogen donor ligand because of the excessive stabilization produced by either the extended $\pi$ con- jugation (4,4'-bipyridine) or the presence of an extra electronegative nitrogen atom (pyridazine and 4-cyanopyridine). The phosphorescence thus reveals strong solvent-polarity dependence, which results in a large shift in emission wavelength, e.g. from 560 (in $\mathrm{C}_{6} \mathrm{H}_{12}$ ) to $665 \mathrm{~nm}$ (in $\mathrm{CH}_{3} \mathrm{CN}$ ) and from 603 (in $\mathrm{C}_{6} \mathrm{H}_{12}$ ) to $710 \mathrm{~nm}$ (in $\mathrm{CH}_{3} \mathrm{CN}$ ) for complexes 25 and 27, respectively. These results clearly demonstrate that a simple derivatization of the axial N-heterocyclic ligand drastically alters the excitation properties per se from intraligand charge transfer (ILCT) to the LLCT transition. The latter exhibits remarkable LLCT phosphorescence solvatochromism, so that a broad range of color tunability was achieved. Future applications to probe molecular/metal ion recognition will be of great interest and these can be achieved by applying the mechanism that incorporates solvent-polarity dependent interplay between ILCT and $\mathrm{LLCT}^{[35]}$

\section{Diphosphane Osmium Derivatives}

An optimized synthesis was performed by the treatment of $\mathrm{Os}_{3}(\mathrm{CO})_{12}$ with at least 6 equiv. pyridyl azole in anhydrous diethylene glycol monoethyl ether (DGME) at 180$190{ }^{\circ} \mathrm{C}$, followed by the addition of a decarbonylation reagent, $\mathrm{Me}_{3} \mathrm{NO}$, and the phosphane ligands in sequences. ${ }^{[36]}$ This one-pot synthesis strategy gives the desired Os ${ }^{\mathrm{II}}$ complexes 28-33 in good yields $(>70 \%)$, and hence has a great advantage as it can be scaled up for possible industrial application. ${ }^{[37]}$ 


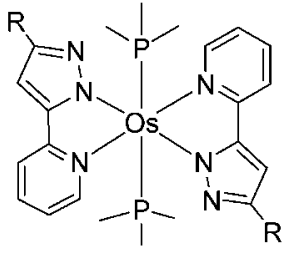

28: $\mathrm{R}=\mathrm{CF}_{3}, \mathrm{P}=\mathrm{PPh}_{2} \mathrm{Me}$

29: $\mathrm{R}=\mathrm{CF}_{3}, \mathrm{P}=\mathrm{PPhMe}_{2}$

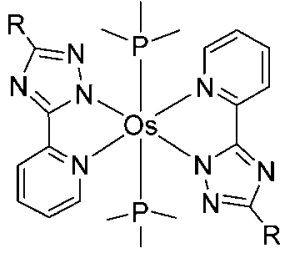

30: $R=t B u, P=P P h_{2} M e$

31: $\mathrm{R}=\mathrm{CF}_{3}, \mathrm{P}=\mathrm{PPh}_{2} \mathrm{Me}$

32: $\mathrm{R}=\mathrm{C}_{3} \mathrm{~F}_{7}, \mathrm{P}=\mathrm{PPh}_{2} \mathrm{Me}$

33: $\mathrm{R}=\mathrm{C}_{3} \mathrm{~F}_{7}, \mathrm{P}=\mathrm{PPhMe}_{2}$
Figure 5 shows an ORTEP diagram of $\mathbf{2 8}$, in which the metal atom is located at a crystallographic center of inversion. The two chelating pyrazolate ligands establish a nearly planar $\mathrm{OsN}_{4}$ basal arrangement, together with two $\mathrm{PPh}_{2} \mathrm{Me}$ ligands located at the trans positions. The planar ligand arrangement is analogous to those of the porphinato ligand in metalloporphyrins such as $\left[\mathrm{Os}(\mathrm{TTP})\left(\mathrm{PPh}_{3}\right)_{2}\right](\mathrm{TTP}=$ mesotetraphenylporphinate) and $[\mathrm{Os}(\mathrm{TPP})(\mathrm{CO})(\mathrm{Im})](\mathrm{Im}=1$ methylimidazole). ${ }^{[38]}$ The measured Os- $\mathrm{N}_{(\mathrm{pz})}$ distances of 2.073(2) $\AA$ in $\mathbf{2 8}$ are slightly shorter than the respective Os$\mathrm{N}_{\text {(py) }}$ bond lengths of 2.090(2) $\AA$; both bond lengths fall in the range expected for a typical $\mathrm{N} \rightarrow \mathrm{Os}^{\mathrm{II}}$ dative bond. Of particular interest are the relatively weak nonbonding contacts $(\mathrm{N} 3 \mathrm{~A} \cdots \mathrm{C} 1=3.305 \AA$ and $\mathrm{N} 3 \mathrm{~A} \cdots \mathrm{H} 1$ ca. $2.50 \AA)$ observed between the ortho-hydrogen atom of the pyridyl moiety and the $\mathrm{N}$ atom of the nearby pyrazolate fragment. It is speculated that this H-bonding, to a certain extent, is akin to that observed in the cobaloxime complexes. ${ }^{[39]}$

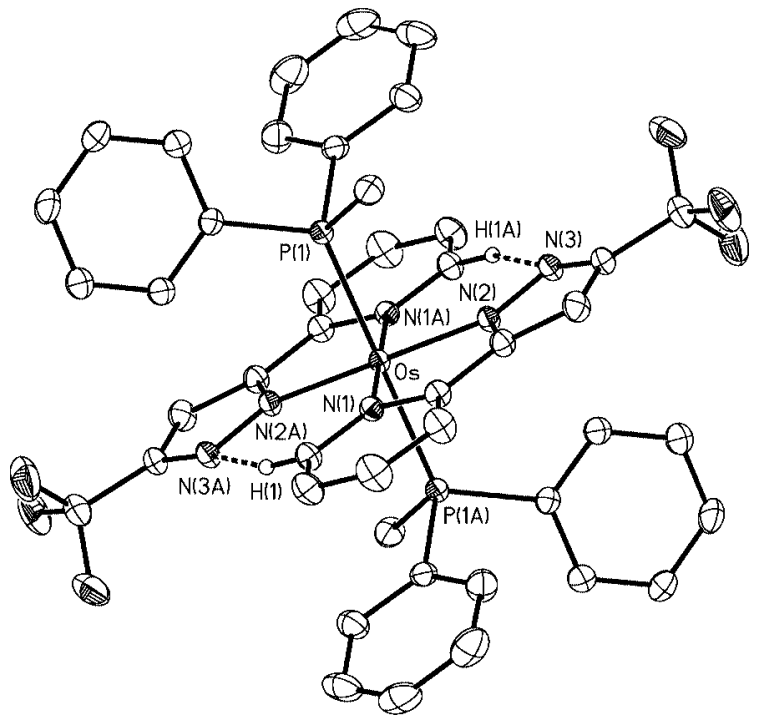

Figure 5. ORTEP diagram of 28; selected distances: Os- $\mathrm{P}(1)=$ $2.3616(5)$, Os $-\mathrm{N}(1)=2.090(2)$, Os$-\mathrm{N}(2)=2.073(2), \mathrm{N}(2)-\mathrm{N}(3)=$ $1.349(2), \mathrm{N}(3) \cdots \mathrm{H}(1 \mathrm{~A})=2.508 \AA$ and angles: $\mathrm{N}(1)-\mathrm{Os}-\mathrm{N}(2)=$ $76.48(7), \mathrm{N}(1)-\mathrm{Os}-\mathrm{N}(2 \mathrm{~A})=103.52(7)^{\circ}$.

As indicated in Table 5, the UV/Vis spectra of these osmium complexes show similar patterns, with three notable absorption maxima. The highest energy band, observed at ca. $400 \mathrm{~nm}$, is naturally assigned to the spin-allowed ${ }^{1} \pi \pi^{*}$ transition. The next lower energy absorption band, around $454-466 \mathrm{~nm}$, can be ascribed to a spin-allowed metal-toligand charge transfer $\left({ }^{1} \mathrm{MLCT}\right)$ transition, while the third lowest energy band can be assigned to a state involving a mixture of both ${ }^{3} \pi \pi^{*}$ and ${ }^{3}$ MLCT characters.

Table 5. Photophysical properties of complexes $\mathbf{2 8}-\mathbf{3 3}$ in $\mathrm{CH}_{2} \mathrm{Cl}_{2}$ and solid state at room temperature.

\begin{tabular}{lllll}
\hline & Abs. $\lambda_{\max }[\mathrm{nm}]$ & PL $\lambda_{\max }[\mathrm{nm}]$ & Q.Y. $\Phi^{[\mathrm{a}]}$ & $\tau[\mathrm{ns}]^{[\mathrm{a}]}$ \\
\hline $\mathbf{2 8}$ & $405,454,542$ & $617(618)^{[\mathrm{a}]}$ & $0.50(0.21)$ & $855(631)$ \\
$\mathbf{2 9}$ & $411,456,553$ & $632(655)$ & $0.19(0.29)$ & $725(610)$ \\
$\mathbf{3 0}$ & $406,466,560$ & $649(670)$ & $0.25(0.10)$ & $634(440)$ \\
$\mathbf{3 1}$ & $405,457,543$ & $617(631)$ & $0.62(0.24)$ & $960(180)$ \\
$\mathbf{3 2}$ & $403,457,545$ & $614(618)$ & $0.76(0.36)$ & $940(580)$ \\
$\mathbf{3 3}$ & $410,465,550$ & $629(634)$ & $0.50(0.21)$ & $810(910)$ \\
\hline
\end{tabular}

[a] Data in parentheses are measured in the solid state at room temperature.

For the emission spectra, in comparison with $\mathbf{2 8}$, which is coordinated by two $\mathrm{PPh}_{2} \mathrm{Me}$ ligands, complex 29, bearing the $\mathrm{PPhMe}_{2}$ groups, reveals a ca. $15-\mathrm{nm}$ bathochromic shift in $\lambda_{\max }$ that can qualitatively be rationalized by an increase in the $\mathrm{Os}^{\mathrm{II}} \mathrm{d} \pi$ energy level as a result of the poor $\pi$-accepting strength of the $\mathrm{PPhMe}_{2}$ ligands (see Table 5). Complexes 28 and 31, both possessing two $\mathrm{PPhMe}_{2}$ ligands, exhibit nearly identical emission in solution, $\lambda_{\max }=617 \mathrm{~nm}$. This is due to the fact that the triazolate fragment, which is more electron withdrawing relative to pyrazolate, exerts an equal amount of stabilization to both HOMO and LUMO, which are located at the $\mathrm{Os}^{\mathrm{II}}$ metal center and the adjacent pyridyl site, respectively. Moreover, changing the substituent on the triazolate from tert-butyl (30) to $\mathrm{CF}_{3}(\mathbf{3 1})$ and then to $\mathrm{C}_{3} \mathrm{~F}_{7}$ (32) causes a notable blue-shift as a result of the increase in the MLCT gap by lowering the metal $\mathrm{d} \pi$ energy level.

Moreover, the observed lifetimes of ca. $0.6-0.9 \mu$ s in degassed $\mathrm{CH}_{2} \mathrm{Cl}_{2}$ solution are considerably shorter than those of other reported red emitting $\mathrm{Ir}^{\mathrm{III}}$ complexes. ${ }^{[0]}$ This, in combination with decent quantum yields $>0.1$, implies that the OLED devices fabricated using this class of osmium complexes could exhibit reduced triplet-triplet annihilation at the higher driving voltage. ${ }^{[7,41]}$

For the preparation of light-emitting devices, we incorporated the osmium phosphor $\mathbf{2 9}$ into a tailor-made blueemitting polyfluorene derivative PF-TPA-OXD. ${ }^{[42]}$ This host polymer, which contains both hole- and electron-transporting side chains, is capable of facilitating charge injection and transport and is suitable for matching the dopanthost energy level to achieve the direct formation and confinement of an exciton at the dopant. This configuration leads to a reduction in the electrical excitation of the host polymer, which in turn decreases the degree of exciton loss arising from nonradiative decay of the host triplet. In practice, PLED devices having the configuration ITO/poly(styrenesulfonate)-doped poly(3,4-ethylenedioxythiophene) (PEDOT) $(35 \mathrm{~nm}) /$ polymer emitting layer $(50-70 \mathrm{~nm})$ and dopant 29/TPBI $(30 \mathrm{~nm}) / \mathrm{Mg}: \mathrm{Ag}(100 \mathrm{~nm}) / \mathrm{Ag}(100 \mathrm{~nm})$ were fabricated, and the optimized dopant concentration of 29 was kept at ca. 1 mol-\%. The PL profile of this device 
contains two components, which are attributed to the polyfluorene emission of the PF-TPA-OXD host and the triplet emission of 29, while the corresponding EL spectra indicate an exclusively dopant emission. The dramatic difference between the PL and EL spectra reveals that the emission would result from direct charge trapping, followed by recombination with opposite charges at the dopant sites. ${ }^{[43]}$ To understand the details of the charge-transport mechanism, the HOMO and LUMO energy of $\mathbf{2 9}$ were estimated by using the onset potentials of the oxidations and reductions obtained with cyclic voltammetry (CV). As shown in Figure 6, holes in this device can easily be injected from PEDOT $(-5.2 \mathrm{eV})^{[44]}$ into the HOMOs $(-5.3 \mathrm{eV})$ of the PFTPA-OXD host upon overcoming a small energy barrier $(0.1 \mathrm{eV})$. For complex 29, the ionization potential is $0.8 \mathrm{eV}$ below the HOMO of PF-TPA-OXD; therefore, holes can be trapped at the dopant site, followed by recombination of opposite charges (electrons) to form excitons. For comparison, this device reached a maximum external quantum efficiency of $8.37 \%$ with a peak brightness of $16720 \mathrm{~cd} \mathrm{~m}^{-2}$. Moreover, a maximum $\eta_{\text {ext }}$ of $12.8 \%$ is reached by using a similar device configuration and by employing a tetraphenylenebiphenyldiamine (TPD) based cross-linkable holetransport layer, as well as a layer of 1,3,5-tris $(N$-phenylbenzimidazol-2-yl)benzene (TPBI) as an electron-transport layer and complex 29 as a dopant emitter. ${ }^{[45]}$

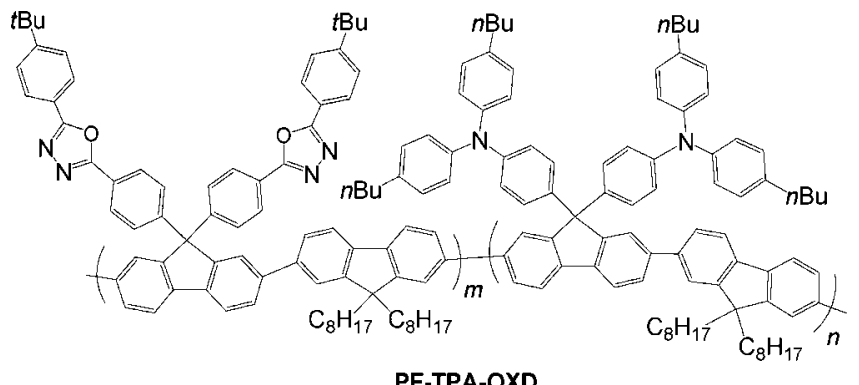

In contrast, ionic red-emitting osmium(II) incorporating various substituted bipyridine ligands were also synthesized and tested for OLED applications. ${ }^{[4]}$ The schematic drawing of two representative osmium(II) complexes, $\mathbf{3 4}$ and $\mathbf{3 5}$, are shown.

This class of complexes features strong red MLCT phosphorescent emission ranging from 611 to $651 \mathrm{~nm}$ and the best quantum yields, up to $45 \% \cdot{ }^{[4]}$ Electrophosphorescent

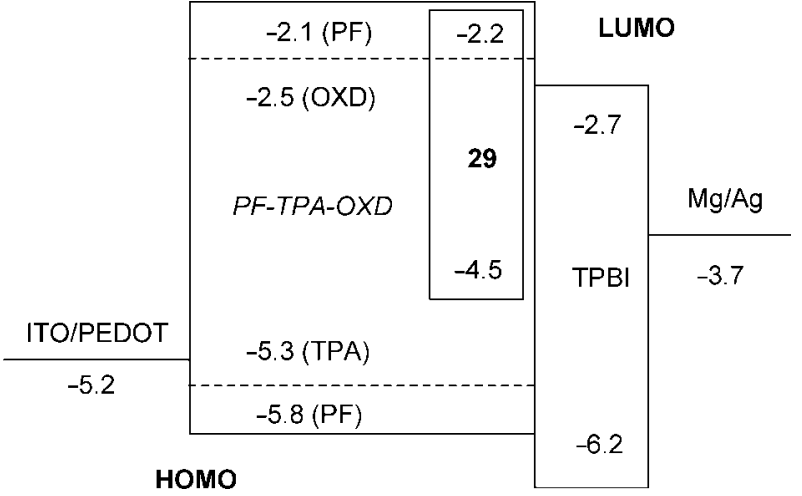

Figure 6. Proposed energy level for the devices having the configuration ITO/PEDOT/29: PF-TPA-OXD/TPBI/Mg:Ag.

devices were demonstrated by using poly $(N$-vinylcarbazole) and 2-tert-butylphenyl-5-biphenyl-1,3,4-oxadiazole (PVK:PBD) as the emitting layer, which give a brightness of $1400 \mathrm{~cd} \mathrm{~m}^{-2}$. The best external quantum efficiency of $2.2 \%$, which corresponds to a photometric efficiency of $1.9 \mathrm{~cd} \mathrm{~A}^{-1}$, was achieved when switching the host matrix from PVK:PBD to a blend host of poly(2-vinylnaphthalene) $(\mathrm{PVN})$ and PBD. ${ }^{[48]}$ Moreover, it is understood that the analogous cationic osmium complexes are capable of trapping both electrons and holes, which facilitates the direct recombination of holes and electrons on the complex sites; however, the resulting devices failed to show any device data comparable to those of previously mentioned neutral osmium complexes such as $\mathbf{2 9}$, even under the conditions using the copolymer PF-TPA-OXD, which is well known for its carefully balanced charge injection and transporting properties. ${ }^{[45]}$ It is obvious that the counterions presented in this class of bipyridine complexes have seriously deteriorated the performance of the device, presumably by affecting the charge trap/transport property of the osmium complexes; hence, the use of ionic emitting materials must be avoided.

For a further comparison, we also took advantage of the high volatility of the neutral osmium(II) complexes to prepare OLEDs using direct thermal evaporation. ${ }^{[37]}$ In this approach, complex 31 was selected for fabricating a series of multilayer devices with the configuration ITO/ $\mathrm{HTL}(40 \mathrm{~nm}) / \mathrm{CBP}: 31(30 \mathrm{~nm}) / \mathrm{BCP}(10 \mathrm{~nm}) / \mathrm{Alq}_{3}(30 \mathrm{~nm}) / \mathrm{LiF}-$ $(1 \mathrm{~nm}) / \mathrm{Al}(150 \mathrm{~nm})$, where $\mathrm{CBP}, \mathrm{BCP}$, and $\mathrm{Alq}_{3}$ are the ab-
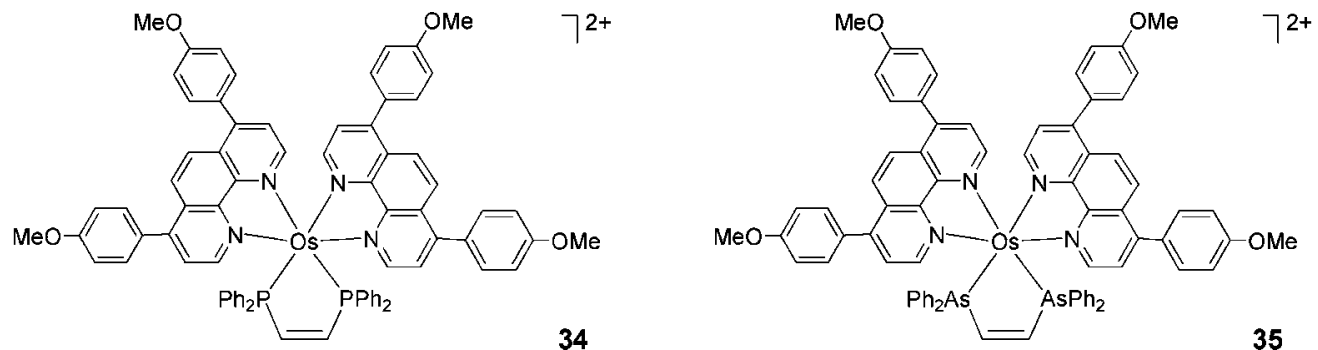
breviations for 4,4'- $N, N^{\prime}$-dicarbazolyl-1,1'-biphenyl, 2,9-dimethyl-4,7-diphenyl-1,10-phenanthroline, and tris(8-hydroxyquinolinato) aluminum(III), respectively. Interestingly, upon switching the hole-transport layer (HTL) from 4,49-bis[ $N$-(1-naphthyl)- $N$-phenylamino]biphenyl

(NPB) and 9,9-bis $\{4$-[bis ( $p$-biphenyl)aminophenyl] $\}$ fluorene (BPAPF),${ }^{[49]}$ a very high initial external quantum efficiency of ca. $20 \%$ and luminous efficiency of $27.8 \mathrm{~cd} \mathrm{~A}^{-1}$ are obtained at $1 \mathrm{mAcm}^{-2}$. These examples stand as some of the best red-emitting phosphorescent OLED devices ever fabricated.

\section{Diphosphane Ruthenium Derivatives}

It is indispensable to have neutral $\mathrm{Ru}^{\mathrm{II}}$ complexes that are suitable for serving as efficient phosphorescent emitters. However, the weaker ligand field strength for the second row transition elements requires the use of strong field ancillary ligands such as phosphane to increase the energy gap of the metal-centered $\mathrm{d}-\mathrm{d}$ transition, such that the radiationless deactivation associated with the metal-metal and/ or metal-ligand bond stretching motion can be significantly suppressed. ${ }^{[19,50]}$ Moreover, the relatively high oxidation potential in $\mathrm{Ru}^{\mathrm{II}}$ versus that of its third-row $\mathrm{Os}^{\mathrm{II}}$ analogues demands the employment of extensively conjugated 1-isoquinolyl-substituted chromophores to compensate for the unfavorable metal oxidation potential for the generation of saturated red emission.

Conversely, a series of $\mathrm{Ru}^{\mathrm{II}}$ complexes 36-40 were synthesized following the synthetic scheme established for their osmium counterparts. ${ }^{[9]}$ Their emission spectra are depicted in Figure 7, while photophysical data are listed in Table 6. Moderate to highly intense luminescence in the solid state

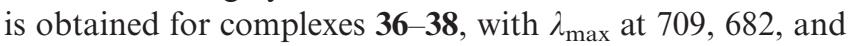

$632 \mathrm{~nm}$, respectively. In good agreement with the ${ }^{3} \mathrm{MLCT}$ emission, the $\mathrm{PPh}_{2} \mathrm{Me}$ derivative 37 exhibits a ca. 27-nm hypsochromic shift in $\lambda_{\max }$ relative to the $\mathrm{PPhMe}_{2}$ anchored 36; this result can qualitatively be rationalized in terms of a decrease in the $\mathrm{Ru}^{\mathrm{II}} \mathrm{d} \pi$ energy level as a result of the increase in $\pi$-accepting strength. For complex 38, an even more notable hypsochromic shift of $50 \mathrm{~nm}$ is achieved. This is apparently caused by the electron-withdrawing effect of the $\mathrm{CF}_{3}$ substituents on pyrazolate, which has a function of lowering the electron density at the $\mathrm{Ru}^{\mathrm{II}}$ metal center.

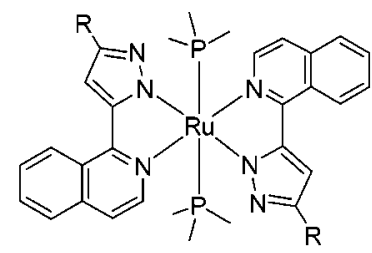

36: $R=t B u, P=P P h M e_{2}$

37: $\mathrm{R}=t \mathrm{Bu}, \mathrm{P}=\mathrm{PPh}_{2} \mathrm{Me}$

38: $\mathrm{R}=\mathrm{CF}_{3}, \mathrm{P}=\mathrm{PPh}_{2} \mathrm{Me}$

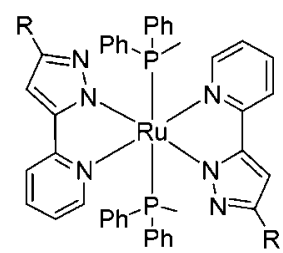

39: $R=t B u$

40: $\mathrm{R}=\mathrm{CF}_{3}$
With the aim of reducing ligand $\pi$ conjugation, replacement of the 1-isoquinolyl pyrazolate ligands with less-conjugated 2-pyridyl pyrazolate counterparts afforded the pyridyl complexes 39 and 40. ${ }^{[51]}$ Although 39 has a low chemical stability upon contact with chlorinated solvents in air, its solid sample gives a faint orange emission at $\lambda_{\max }=$ $568 \mathrm{~nm}$ at room temperature - a result of increasing the emission gap from that of $\mathbf{3 6}\left(\lambda_{\max }=709 \mathrm{~nm}\right)$ by reducing the $\pi$-conjugation of the LUMO orbital.

A further increase in the energy gap for $\mathbf{4 0}$ is expected owing to the presence of an electronegative $\mathrm{CF}_{3}$ substituent on the chelating pyrazolate, which is expected to stabilize the metal $\mathrm{d} \pi$ orbitals by lowering the electron density. This viewpoint can be firmly supported by TD-DFT calcula-

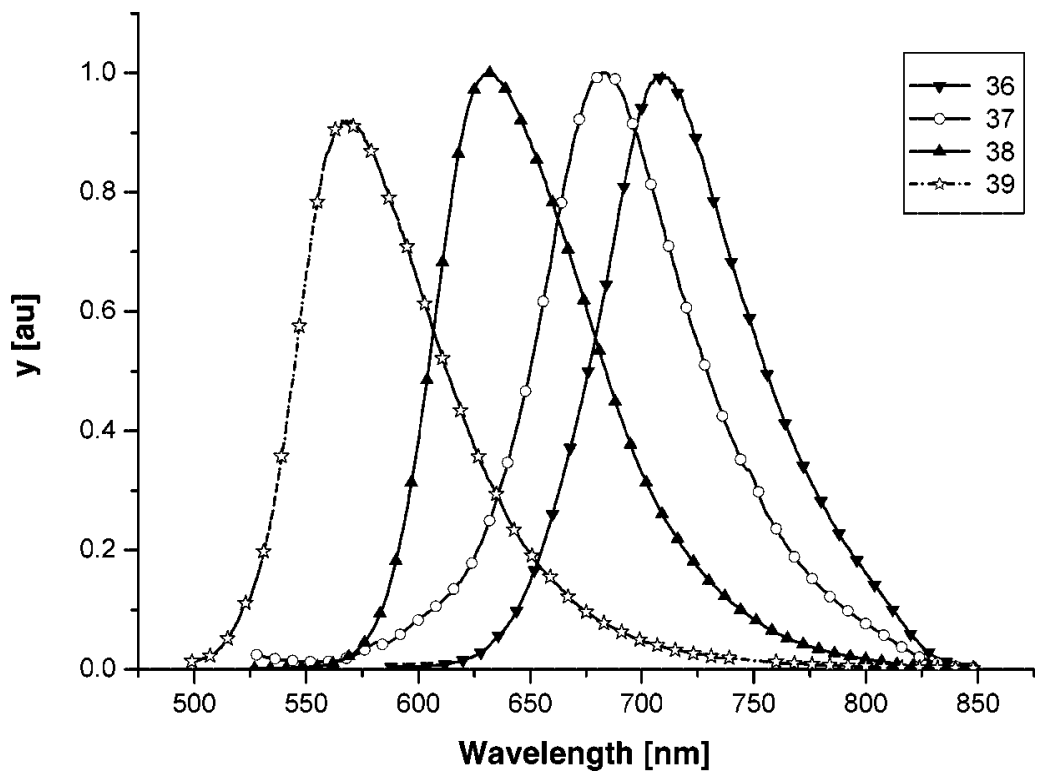

Figure 7. Photoluminescence of $\mathrm{Ru}^{\mathrm{II}}$ phosphors as solid film at room temperature. 
Table 6. Photophysical properties of complexes $36-\mathbf{4 0}$ in $\mathrm{CH}_{2} \mathrm{Cl}_{2}$ and solid state at room temperature.

\begin{tabular}{lllll}
\hline & Abs. $\lambda_{\max }[\mathrm{nm}]\left(\varepsilon \times 10^{3}\right)$ & PL $\lambda_{\max }[\mathrm{nm}]^{[\mathrm{a}]}$ & $\Phi^{[\mathrm{a}]}$ & $\tau_{\text {obs. }}[\mu \mathrm{s}]^{[\mathrm{a}]}$ \\
\hline $\mathbf{3 6}$ & $336(20), 363(14), 462(13), \approx 580(0.9$, br. $)$ & $718(709)$ & $-(0.02)$ & $-(1.06)$ \\
$\mathbf{3 7}$ & $332(20), 361(15), 455(12), \approx 566(1$, br. $)$ & $700(682)$ & $-(0.02)$ & $-(0.64)$ \\
$\mathbf{3 8}$ & $320(25), 353(13), 446(17), \approx 523(1, \mathrm{br})$ & $636(632)$ & $0.01(0.24)$ & $0.10(1.82)$ \\
$\mathbf{3 9}$ & $309(19), 395(10), 443(1), \approx 493(1, \mathrm{br})$ & $-(568)$ & $-(0.001)$ & $-(0.16)$ \\
$\mathbf{4 0}$ & $297(22), 392(12), \approx 460(0.7$, br. $)$ & - & - & - \\
\hline
\end{tabular}

[a] Data in parentheses are measured in the solid state at room temperature.

tions. As shown by the absorption data listed in Table 6, complex 40 apparently exhibits the highest ${ }^{1}$ MLCT absorption (ca. $460 \mathrm{~nm}$ ) among all other $\mathrm{Ru}^{\mathrm{II}}$ complexes prepared (493-580 nm). The TD-DFT results of $\mathbf{4 0}$ show that the lowest-energy triplet state involves metal dd character $\left(\approx 64 \%\right.$ ), while the typical ${ }^{3}$ MLCT state increases in energy and becomes a second lowest excited state. ${ }^{[51]}$

As for the OLED applications, a multilayer device using 24 wt. $-\%$ of $\mathbf{3 8}$ as a dopant emitter in a CBP host and with NPB as a hole transport layer exhibits saturated red emission with an external quantum efficiency of $5.10 \%$, luminous efficiency of $5.74 \mathrm{~cd} \mathrm{~A}^{-1}$, and power efficiency of $2.621 \mathrm{~m} \mathrm{~W}^{-1}$, while incorporation of a thin layer of PEDOT/ PSS between ITO and NPB gives an optimized result with external quantum efficiency of $7.03 \%$, luminous efficiency of $8.02 \mathrm{~cd} \mathrm{~A}^{-1}$, and power efficiency of $2.74 \mathrm{~lm} \mathrm{~W}^{-1}$ at $20 \mathrm{~mA} \mathrm{~cm}^{-2}$. The nonionic nature, high emission quantum efficiency, and short radiative lifetime are believed to be the key factors responsible for this unprecedented behavior. In contrast, fabrication of OLED devices using the ionic emitting materials can only produce devices with poor performances, ${ }^{[52]}$ although the related $\mathrm{Ru}^{\mathrm{II}}$ complexes have been extensively utilized in light-emitting electrochemical cells (LECs), ${ }^{[53]}$ in which the excessive mobile counterions facilitate the electrochemical redox processes required for generation of high efficiency steady-state radiance.

\section{Concluding Remarks}

With the aim of optimizing the performance of organic light-emitting diodes, research on the transition-metal complexes evidently still offers great prospects. In this review, we demonstrate the power of $\mathrm{Os}^{\mathrm{II}}$ and $\mathrm{Ru}^{\mathrm{II}}$ fragments in supporting a variety of ligands, such as those of [Os(CO) $)_{3}$ substituted diketonate or quinolinolate complexes, [Os$(\mathrm{CO})_{2}$ ] derivatives involving diimine or pyridyl azolate complexes, diphosphane-substituted osmium and ruthenium derivatives, which result in complexes with great luminescent properties. We also show the importance of merging theoretical and experimental observations, providing timely feedback for further rational design of numerous functionalized luminescent complexes. In this regard, we formulate a fundamental issue regarding a generalized radiationless deactivation process, i.e. the first-order perturbation incorporating the spin-orbit coupling from various orbital configurations (e.g. ${ }^{3} \pi \pi^{*}$ or ${ }^{3} \mathrm{~d}_{\pi} \pi^{*}$ ). In this approach, mixing between ${ }^{3} \pi \pi^{*}$ and ${ }^{3} \mathrm{~d}_{\pi} \pi^{*}$ apparently gains a certain preference for facilitating the $S_{1} \rightarrow T_{1}$ intersystem crossing rate (and likewise the $T_{1} \rightarrow S_{1}$ process). As a result, the intersystem crossing rate can be qualitatively predicted through theoretical frontier orbital analyses in combination with, for example, X-ray structural determination. As for the case of neutral $\mathrm{Ru}^{\mathrm{II}}$ complexes, we trust that the design of ligands for averting the incorporation of metal dd character into the lowest triplet state plays a key role in increasing the luminescent behavior; this strategy should be equally applicable to other systems incorporating second-row transition-metal elements.

In view of OLED applications, a broad range of color tuning from red to blue has been achieved by derivatization of either pyridine or azolate segments as well as by variation in the electronic properties of the central metal atom by adjusting the ancillary ligands. Accordingly, we have reviewed a number of C-linked pyridyl azolate based $\mathrm{Os}^{\mathrm{II}}$ and $\mathrm{Ru}^{\mathrm{II}}$ complexes with regard to making OLEDs with excellent performance. It is thus possible that these pyridyl azolate based metal complexes, after full optimization, will eventually meet the expected industrial demand. Further extension of the chapter of $\mathrm{Os}^{\mathrm{II}}$ transition-metal complexes is also of great interest. On the basis of a similar principle, coarse as well as fine-tuning of ligands, especially the pyridyl azolate based complexes, toward the near-IR region with high luminescent efficiency is feasible, making possible their future applications in other fields such as near-IR imaging, optical communication, and photovoltaic systems, etc. We thus believe that the results as well as the perspectives presented in this review should spur continuous interest in the design and preparation of luminescence materials incorporating both $\mathrm{Os}^{\mathrm{II}}$ and $\mathrm{Ru}^{\mathrm{II}}$ elements.

[1] a) A. M. Powe, K. A. Fletcher, N. N. St. Luce, M. Lowry, S. Neal, M. E. McCarroll, P. B. Oldham, L. B. McGown, I. M. Warner, Anal. Chem. 2004, 76, 4614; b) W. R. Browne, N. M. O’Boyle, J. J. McGarvey, J. G. Vos, Chem. Soc. Rev. 2005, 34 , 641; c) J. N. Demas, B. A. DeGraff, Coord. Chem. Rev. 2001, $211,317$.

[2] a) S. Leininger, B. Olenyuk, P. J. Stang, Chem. Rev. 2000, 100, 853; b) S.-S. Sun, A. J. Lees, Coord. Chem. Rev. 2002, 230, 171; c) S. M. Woessner, J. B. Helms, J. F. Houlis, B. P. Sullivan, Inorg. Chem. 1999, 38, 4380; d) V. W.-W. Yam, Chem. Commun. 2001, 789.

[3] a) F. Li, M. Zhang, J. Feng, G. Cheng, Z. Wu, Y. Ma, S. Liu, J. Sheng, S. T. Lee, Appl. Phys. Lett. 2003, 83, 365; b) D. Xu, K. T. Khin, W. E. Van der Veer, J. W. Ziller, B. Hong, Chem. 
Eur. J. 2001, 7, 2425; c) P. Spellane, R. J. Watts, A. Vogler, Inorg. Chem. 1993, 32, 5633.

[4] a) M. A. Baldo, D. F. O'Brien, Y. You, A. Shoustikov, S. Sibley, M. E. Thompson, S. R. Forrest, Nature 1998, 395, 151; b) E. Holder, B. M. W. Langeveld, U. S. Schubert, Adv. Mater. 2005, 17, 1109; c) X. Gong, J. C. Ostrowski, G. C. Bazan, D. Moses, A. J. Heeger, Appl. Phys. Lett. 2002, 81, 3711.

[5] a) Y. Kawamura, K. Goushi, J. Brooks, J. J. Brown, H. Sasabe, C. Adachi, Appl. Phys. Lett. 2005, 86, 071104; b) C. Adachi, M. A. Baldo, M. E. Thompson, S. R. Forrest, J. Appl. Phys. 2001, 90, 5048.

[6] a) M. A. Baldo, M. E. Thompson, S. R. Forrest, Pure Appl. Chem. 1999, 71, 2095; b) C. Adachi, M. A. Baldo, S. R. Forrest, M. E. Thompson, Appl. Phys. Lett. 2000, 77, 904.

[7] a) H. Zhen, C. Jiang, W. Yang, J. Jiang, F. Huang, Y. Cao, Chem. Eur. J. 2005, 11, 5007; b) J. Kalinowski, J. Mezyk, F. Meinardi, R. Tubino, M. Cocchi, D. Virgili, Appl. Phys. Lett. 2005, 98, 063532; c) M. A. Baldo, C. Adachi, S. R. Forrest, Phys. Rev. B 2000, 62, 10967

[8] a) S.-W. Lai, C.-M. Che, Top. Curr. Chem. 2004, 241, 27; b) B. Ma, P. I. Djurovich, M. E. Thompson, Coord. Chem. Rev. 2005, 249, 1501; c) J. Kavitha, S.-Y. Chang, Y. Chi, J.-K. Yu, Y.-H. Hu, P.-T. Chou, S.-M. Peng, G.-H. Lee, Y.-T. Tao, C.-H. Chien, A. J. Carty, Adv. Funct. Mater. 2005, 15, 223.

[9] Y.-L. Tung, S.-W. Lee, Y. Chi, L.-S. Chen, C.-F. Shu, F.-I. Wu, A. J. Carty, P.-T. Chou, S.-M. Peng, G.-H. Lee, Adv. Mater. 2005, 17, 1059.

[10] E. A. Medlycott, G. S. Hanan, Chem. Soc. Rev. 2005, 34, 133.

[11] a) V. W.-W. Yam, V. C.-Y. Lau, L.-X. Wu, J. Chem. Soc. Dalton Trans. 1998, 1461; b) A. Vogler, H. Kunkely, Coord. Chem. Rev. 2000, 200-202, 991; c) D. R. Striplin, G. A. Crosby, Coord. Chem. Rev. 2001, 211, 163.

[12] Y.-L. Chen, S.-W. Li, Y. Chi, Y.-M. Cheng, S.-C. Pu, Y.-S. Yeh, P.-T. Chou, ChemPhysChem 2005, 6, 2012.

[13] J. Li, P. I. Djurovich, B. D. Alleyne, M. Yousufuddin, N. N. Ho, J. C. Thomas, J. C. Peters, R. Bau, M. E. Thompson, Inorg. Chem. 2005, 44, 1713 .

[14] Y.-L. Chen, C. Sinha, I.-C. Chen, K.-L. Liu, Y. Chi, J.-K. Yu, P.-T. Chou, T.-H. Lu, Chem. Commun. 2003, 3046.

[15] J.-K. Yu, Y.-M. Cheng, Y.-H. Hu, P.-T. Chou, Y.-L. Chen, S.W. Lee, Y. Chi, J. Phys. Chem. B 2004, 108, 19908.

[16] a) D. S. Tyson, C. R. Luman, X. Zhou, F. N. Castellano, Inorg. Chem. 2001, 40, 4063; b) L.-Q. Song, J. Feng, X.-S. Wang, J.H. Yu, Y.-J. Hou, P.-H. Xie, B.-W. Zhang, J.-F. Xiang, X.-C. Ai, J.-P. Zhang, Inorg. Chem. 2003, 42, 3393; c) W. Goodall, J. A. G. Williams, Chem. Commun. 2001, 2514; d) A. Del Guerzo, S. Leroy, F. Fages, R. H. Schmehl, Inorg. Chem. 2002, 41, 359 .

[17] a) S. Shtykov, G. Melnikov, I. Goryacheva, J. Mol. Struct. 1999, 482-483, 699; b) J. A. Murillo Pulgarin, A. A. Molina, M. T. Alanon Pardo, Anal. Chim. Acta 2000, 423, 85; c) T. Perez-Ruiz, C. Martinez-Lozano, V. Tomas, J. Martin, J. Pharm. Biomed. Anal. 2003, 32, 225.

[18] Y. Sato, M. Morimoto, H. Segawa, T. Shimidzu, J. Phys. Chem. 1995, 99, 35.

[19] S. Zalis, I. R. Farrell, A. Vlcek, J. Am. Chem. Soc. 2003, 125, 4580.

[20] J. R. Lakowicz, Principles of Fluorescence Spectroscopy, Kluwer Academic/Plenum Publishers, New York, 1999, ch. 6.

[21] Y.-M. Cheng, Y.-S. Yeh, M.-L. Ho, P.-T. Chou, P.-S. Chen, Y. Chi, Inorg. Chem. 2005, 44, 4594.

[22] a) M. Muccini, M. A. Loi, K. Kenevey, R. Zamboni, N. Masciocchi, A. Sironi, Adv. Mater. 2004, 16, 861; b) V. A. Montes, G. Li, R. Pohl, J. Shinar, P. Anzenbacher Jr, Adv. Mater. 2004, 16, 2001; c) M. Colle, J. Gmeiner, W. Milius, H. Hillebrecht, W. Brutting, Adv. Funct. Mater. 2003, 13, 108.

[23] R. Ballardini, G. Varani, M. T. Indelli, F. Scandola, Inorg. Chem. 1986, 25, 3858.

[24] M. Klessinger, M J. Michl, Excited States and Photochemistry of Organic Molecules, VCH, New York, 1995, ch. 2.
[25] H. Kunkely, A. Vogler, Chem. Phys. Lett. 2003, 376, 226.

[26] Y.-L. Chen, S.-W. Lee, Y. Chi, K.-C. Hwang, S. B. Kumar, Y.H. Hu, Y.-M. Cheng, P.-T. Chou, S.-M. Peng, G.-H. Lee, S.-J. Yeh, C.-T. Chen, Inorg. Chem. 2005, 44, 4287.

[27] a) P. A. Anderson, F. R. Keene, T. J. Meyer, J. A. Moss, G. F. Strouse, J. A. Treadway, J. Chem. Soc. Dalton Trans. 2002, 3820; b) G. H. Allen, R. P. White, D. P. Rillema, T. J. Meyer, J. Am. Chem. Soc. 1984, 106, 2613.

[28] P.-C. Wu, J.-K. Yu, Y.-H. Song, Y. Chi, P.-T. Chou, S.-M. Peng, G.-H. Lee, Organometallics 2003, 22, 4938.

[29] J.-K. Yu, Y.-H. Hu, Y.-M. Cheng, P.-T. Chou, S.-M. Peng, G.H. Lee, A. J. Carty, Y.-L. Tung, S.-W. Lee, Y. Chi, C.-S. Liu, Chem. Eur. J. 2004, 10, 6255.

[30] a) A. Vogler, H. Kunkely, Top. Curr. Chem. 2001, 213, 143; b) M. M. Glezen, A. J. Lees, J. Am. Chem. Soc. 1988, 110, 3892.

[31] P. J. Hay, J. Phys. Chem. A 2002, 106, 1634.

[32] N. J. Turro, Modern Molecular Photochemistry, University Science Books, Mill Valley, California, 1991, ch. 6, p. 170.

[33] a) A. B. Tamayo, B. D. Alleyne, P. I. Djurovich, S. Lamansky, I. Tsyba, N. N. Ho, R. Bau, M. E. Thompson, J. Am. Chem. Soc. 2003, 125, 7377; b) T. Karatsu, T. Nakamura, S. Yagai, A. Kitamura, K. Yamaguchi, Y. Matsushima, T. Iwata, Y. Hori, T. Hagiwara, Chem. Lett. 2003, 32, 886.

[34] S.-W. Li, Y.-M. Cheng, Y.-S. Yeh, C.-C. Hsu, P.-T. Chou, S.M. Peng, G.-H. Lee, Y.-L. Tung, P.-C. Wu, Y. Chi, F.-I. Wu, C.-F. Shu, Chem. Eur. J. 2005, 11, 6347.

[35] M.-L. Ho, F.-M. Hwang, P.-N. Chen, Y.-H. Hu, Y.-M. Cheng, K.-S. Chen, G.-H. Lee, Y. Chi, P.-T. Chou, Org. Biomol. Chem. 2006, 4, 98.

[36] Y.-L. Tung, P.-C. Wu, C.-S. Liu, Y. Chi, J.-K. Yu, Y.-H. Hu, P.-T. Chou, S.-M. Peng, G.-H. Lee, Y. Tao, A. J. Carty, C.-F. Shu, F.-I. Wu, Organometallics 2004, 23, 3745.

[37] Y.-L. Tung, S.-W. Lee, Y. Chi, Y.-T. Tao, C.-H. Chien, Y.-M. Cheng, P.-T. Chou, S.-M. Peng, C.-S. Liu, J. Mater. Chem. 2005, 15, 460 .

[38] C. M. Che, T. F. Lai, W. C. Chung, W. P. Schaefer, H. B. Gray, Inorg. Chem. 1987, 26, 3907.

[39] B. D. Gupta, V. Singh, R. Yamuna, T. Barclay, W. Cordes, Organometallics 2003, 22, 2670.

[40] a) A. Tsuboyama, H. Iwawaki, M. Furugori, T. Mukaide, J. Kamatani, S. Igawa, T. Moriyama, S. Miura, T. Takiguchi, S. Okada, M. Hoshino, K. Ueno, J. Am. Chem. Soc. 2003, 125, 12971; b) F.-M. Hwang, H.-Y. Chen, P.-S. Chen, C.-S. Liu, Y. Chi, C.-F. Shu, F.-I. Wu, P.-T. Chou, S.-M. Peng, G.-H. Lee, Inorg. Chem. 2005, 44, 1344.

[41] F.-I. Wu, P.-I. Shih, C.-F. Shu, Y.-L. Tung, Y. Chi, Macromolecules 2005, 38, 9028.

[42] F.-I. Wu, P.-I. Shih, Y.-H. Tseng, G.-Y. Chen, C.-H. Chien, C.F. Shu, Y.-L. Tung, Y. Chi, A. K.-Y. Jen, J. Phys. Chem. B 2005, 109, 14000.

[43] a) Y.-Y. Noh, C.-L. Lee, J.-J. Kim, K. Yase, J. Chem. Phys. 2003, 118, 2853; b) M. Uchida, C. Adachi, T. Koyama, Y. Taniguchi, J. Appl. Phys. 1999, 86, 1680; c) F.-C. Chen, S. C. Chang, G. He, S. Pyo, Y. Yang, M. Kurotaki, J. Kido, J. Polym. Sci., Part B: Polym. Phys. 2003, 41, 2681.

[44] T. M. Brown, J. S. Kim, R. H. Friend, F. Cacialli, R. Daik, W. J. Feast, Appl. Phys. Lett. 1999, 75, 1679.

[45] Y.-H. Niu, Y.-L. Tung, Y. Chi, C.-F. Shu, J. H. Kim, B. Chen, J. Luo, A. J. Carty, A. K.-Y. Jen, Chem. Mater. 2005, 17, 3532.

[46] a) B. Carlson, G. D. Phelan, W. Kaminsky, L. Dalton, X. Jiang, S. Liu, A. K.-Y. Jen, J. Am. Chem. Soc. 2002, 124, 14162; b) X. Jiang, A. K.-Y. Jen, B. Carlson, L. R. Dalton, Appl. Phys. Lett. 2002, 80, 713 .

[47] X. Jiang, A. K. Y. Jen, B. Carlson, L. R. Dalton, Appl. Phys. Lett. 2002, 81, 3125

[48] J. H. Kim, M. S. Liu, A. K.-Y. Jen, B. Carlson, L. R. Dalton, C.-F. Shu, R. Dodda, Appl. Phys. Lett. 2003, 83, 776.

[49] C.-W. Ko, Y.-T. Tao, Synth. Met. 2002, 126, 37.

[50] M. K. Nazeeruddin, R. Humphry-Baker, D. Berner, S. Rivier, L. Zuppiroli, M. Graetzel, J. Am. Chem. Soc. 2003, 125, 8790. 
[51] Y.-L. Tung, L.-S. Chen, Y. Chi, S.-W. Lee, P.-T. Chou, Y.-M. Cheng, E. Y. Li, G.-H. Lee, C.-F. Shu, F.-I. Wu, A. J. Carty, C.-S. Liu, Adv. Funct. Mater. 2006, 16, 1615-1626.

[52] a) H. Xia, C. Zhang, X. Liu, S. Qiu, P. Lu, F. Shen, J. Zhang, Y. Ma, J. Phys. Chem. B 2004, 108, 3185; b) J. Yang, K. C. Gordon, Chem. Phys. Lett. 2003, 372, 577.

[53] a) G. Kalyuzhny, M. Buda, J. McNeill, P. Barbara, A. J. Bard, J. Am. Chem. Soc. 2003, 125, 6272; b) H. Rudmann, S. Shim- ada, M. F. Rubner, J. Appl. Phys. 2003, 94, 115; c) J. D. Slinker, A. A. Gorodetsky, M. S. Lowry, J. Wang, S. Parker, R. Rohl, S. Bernhard, G. G. Malliaras, J. Am. Chem. Soc. 2004, 126, 2763.

Received: April 24, 2006 Published Online: July 13, 2006 